\title{
Molecular Signatures Associated With the Development of Pulmonary Toxicities in Mesothelioma Patients Treated With Radical Hemithoracic Radiation Therapy
}

\section{Sergio Crovella}

Qatar University

Alberto Relevant

National Cancer Institute CRO Aviano: Centro di Riferimento Oncologico

Elena Muraro

National Cancer Institute CRO Aviano: Centro di Riferimento Oncologico

Ronald Moura

Burlo Garofalo Pediatric Institute: IRCCS materno infantile Burlo Garofolo

Lucas Brandão

Burlo Garofalo Pediatric Institute: IRCCS materno infantile Burlo Garofolo

Marco Trovò

Udine University Health Integrated Agency: Azienda Sanitaria Universitaria Integrata di Udine

Agostino Steffan

National Cancer Institute CRO Aviano: Centro di Riferimento Oncologico

Paola Zacchi

University of Trieste Department of Life Sciences

Giuliano Zabucchi

University of Trieste Department of Life Sciences

\section{Emilio Minatel}

National Cancer Institute CRO Aviano: Centro di Riferimento Oncologico

Violetta Borelli ( $\sim$ borelliv@units.it )

University of Trieste: Universita degli Studi di Trieste https://orcid.org/0000-0002-8166-3513

\section{Research}

Keywords: Mesothelioma, Radical Hemithoracic Radiotherapy, Pulmonary Toxicities, Whole Exome Posted Date: July 7th, 2021

DOI: https://doi.org/10.21203/rs.3.rs-652408/v1 
License: (c) (i) This work is licensed under a Creative Commons Attribution 4.0 International License. Read Full License 
1 Molecular signatures associated with the development of pulmonary toxicities in mesothelioma patients treated with radical hemithoracic radiation therapy

Sergio Crovella *, Alberto Relevant *, Elena Muraro, Ronald Rodrigues Moura, Lucas Brandão, Marco

Trovò, Agostino Steffan, Paola Zacchi, Giuliano Zabucchi, Emilio Minatel, Violetta Borelli $\bowtie$

Sergio Crovella - Biological and Environmental Sciences, University of Qatar, Doha, State of Qatarcrovelser@gmail.com

Alberto Revelant - Department of Radiation Oncology, Centro di Riferimento Oncologico di Aviano (CRO) IRCCS, Aviano, Italy - alberto.revelant@cro.it

Keywords: Mesothelioma, Radical Hemithoracic Radiotherapy, Pulmonary Toxicities, Whole Exome IRCCS, Aviano, Italy - eminatel@cro.it

Elena Muraro - Immunopathology and Biomarker Unit, Department of Translational Research, Centro di Riferimento Oncologico di Aviano (CRO) IRCCS, Aviano, Italy - emuraro@cro.it

Ronald Rodrigues Moura- Institute for Maternal and Child Health - IRCCS "Burlo Garofolo", Trieste, Italy - ronaldmoura1989@gmail.com

Lucas Brandão - Institute for Maternal and Child Health - IRCCS "Burlo Garofolo", Trieste, Italy lucabrand@gmail.com

Marco Trovò-Udine Academic Hospital, Udine, Italy - marco.trovo@asuiud.sanita.fvg.it Agostino Steffan - Immunopathology and Biomarker Unit, Department of Translational Research, Centro di Riferimento Oncologico di Aviano (CRO) IRCCS, Aviano, Italy - asteffan@cro.it

Paola Zacchi, Department of Life Sciences, University of Trieste, Italy - pzacchi@units.it Giuliano Zabucchi - Department of Life Sciences, University of Trieste, Italy - zabucchi@units.it Violetta Borelli ${ }^{\bowtie}$ - Department of Life Sciences, University of Trieste, Italy-borelliv@units.it

*These authors contributed equally

${ }^{\square}$ Corresponding author 
Abstract

Background. Radical Hemithoracic Radiotherapy (RHR), after lung-sparing surgery, has recently become a concrete therapeutic option for malignant pleural mesothelioma (MPM), an asbestos-related, highly aggressive tumor with increasing incidence and poor prognosis. Although the toxicity associated to this treatment has been reduced, it is still not negligible and must be considered when treating patients. Genetic factors appear to play a role determining radiotherapy toxicity. The aim of this study is the identification of genetic markers able to predict the relative susceptibility for newly diagnosed MPM patients to develop lung adverse effects if they were to be treated with RHR.

Methods. The study included individuals with MPM, treated with lung-sparing surgery and neoadjuvant chemotherapy, followed by RHR with curative intent, and followed up prospectively for development of pulmonary toxicity. Due to the impact of grade 3 pulmonary toxicities on the quality of life, for further genetic analyses patients were divided into a none or tolerable pulmonary toxicity group (Grade $\leq 2$ ) and a severe pulmonary toxicity group (Grade=3). Whole exome sequencing (WES) was performed to identify genetic variants in biological pathways associated to pulmonary toxicity after radiotherapy.

Results. We identified crucial pathways driving the lung response to ionizing radiations in patients affected by mesothelioma: by affecting both the fibrinolytic activity and RNA editing pathways, irradiation could be responsible of the severe toxicity events reported by some patients, who present specific mutations in genes involved in these pathways.

Conclusions. Our preliminary results could pave the way for the definition of a panel of predictive genomic variants, capable of supporting the management of MPM patients. By allowing for early identification of patients at high risk for treatment-dependent pulmonary toxicity, this predictive tool could play a major role in the design of new therapeutic combinations. 


\section{BACKGROUND}

Malignant pleural mesothelioma (MPM) is an asbestos-related, highly aggressive tumor derived from cells of the pleura, with increasing incidence (expected to peak in the period 2020-2024) (1) and poor prognosis. Such dismal outcome also derives from the complex management of the disease, given that the scientific community still debates about the best protocol to follow, based on the three therapeutic options that are currently available: surgery, radiotherapy and chemotherapy (2-4).

Until recently it was thought that the routine administration of radiotherapy in patients with MPM was not supported by evidence (5). In recent years, modern radiation techniques have been applied postsurgery, allowing for more effective sparing of normal tissue, thus enabling higher radiation doses at the tumor site. Reasearchers from the National Cancer Institute of Aviano have published a series of prospective studies (6-8) proving that radical intensity modulated radiation therapy, after lung-sparing surgery, leads to excellent loco-regional control and survival in MPM patients. A median overall survival (OS) of 25.6 months and a 2-year OS rate of $58 \%$ are among the best results observed in recent studies (9-11), supporting the idea that this approach represents a concrete therapeutic option for MPM.

Although the toxicity associated to these treatments has been drastically reduced, it is still not negligible and must be taken into consideration when treating patients (12). Pulmonary toxicities are very common among mesothelioma patients undergoing radiotherapy on the entire hemithorax even if the treatment is well-tolerated. Albeit infrequent, worse adverse effects, like grade 2 or 3 fibrosis and pulmonary embolism, can be seen, and the management of these toxicities is still challenging.

Improved ways of predicting, prior to treatment, the risk of development of adverse lung effects after radiotherapy may result in more promising personalized treatments and in a reduced incidence and severity of late effects. There is increasing recognition that the cause of normal tissue toxicity is 
multifactorial and includes genetic factors in addition to dosimetric parameters, patient age, smoking history, concurrent treatments, and comorbidities (13-15).

In the last decade, more than one hundred papers have been published addressing possible associations between genetic germline variants and risk of normal tissue toxicity after radiotherapy. With few exceptions, however, these relied on relatively few studies that used a candidate gene approach [single nucleotide polymorphisms (SNPs) analysis] (16), and the association results have not been replicated (17-18).

Recently, genome-wide association analyses (GWAS), including meta-analysis, performed by the Radiogenomics Consortium (RgC; epi.grants.cancer.gov/radiogenomics/) have identified several novel SNPs within genes not previously linked to radiotherapy toxicity, in patients affected by different types of cancers, such as breast, prostate and lung $(19,20)$. Nevertheless, genetic susceptibility to radiotoxicity in nonsyndromic individuals remains poorly understood. To our knowledge, whole exome analysis has not previously been considered as a potential tool to assess the toxicity of radiotherapy for lung/pleural cancer, based on patients' genetic background. So, with the aim of contributing to the identification of a possible role for genetic variantions in the coding and their flanking intronic regions, in the response to radiotherapy in MPM patients, we performed whole exome sequencing, coupled with bioinformatic analysis, to identify not only the genetic variants associated to pulmonary toxicity after radiotherapy, but also to unravel biological pathways that can better elucidate the observed phenotypes.

\section{METHODS}

\section{Study Participants}

The study included individuals with MPM, treated with non-radical surgical treatment, such as partial pleurectomy/decortication (P/D) or biopsy only, and neoadjuvant platinum-based plus pemetrexed 
chemotherapy for MPM, followed by high dose radiation therapy with curative intent, and followed up prospectively for development of (lung/pulmonary) toxicity. Other inclusion criteria were: age $\geq 18$ years, proven gross residual disease after surgery, stage I-IVA (according to TNM stage $7^{\text {th }}$ edition), Eastern Cooperative Oncology Group (ECOG) performance status score 0-2, pulmonary function of at least $50 \%$ of predicted, technical feasibility for delivery of Radical Hemithoracic Radiotherapy (RHR), satisfactory bone marrow function (white blood cells $\geq 2000 / \mu \mathrm{L}$, platelet $\geq 100.000 / \mu \mathrm{L}$, haemoglobin $>$ $10 \mathrm{~g} / \mathrm{dL}$ ). Exclusion criteria were: pathologic contralateral mediastinal nodes (N3), metastatic MPM (Stage IVB), or intra-scissural disease. Tumour histology was classified as epithelioid and non-epithelioid (sarcomatoid and biphasic). All patients were staged by lung and abdomen contrast-enhanced computed tomography (CT) scans and a 18F-fluorodeoxyglucose (18FDG)-positron emission tomography (PET)/CT.

Between August 2014 and May 2018, 49 patients who received Radical Hemithoracic Radiotherapy (RHR) were included in this study. Patients were treated with helical IMRT, delivering the dose with Accuray Tomotherapy System. The radiation therapy technique has previously been described in detail $(7,8,11)$. Patients received $50 \mathrm{~Gy}$ in 25 fractions (except for one case, later described), plus an eventual boost to 60 Gy on PET positive areas.

OS was defined as the time (years) intercourse since randomization to death from any causes, or the last follow-up (until December 2020, 1st), and estimated with the Kaplan-Meier method, p value was calculated with Long-rank test.

This prospective study was conducted according to the ethical principles of the Declaration of Helsinki and approved by the local Ethical Committee (Comitato Etico Indipendente del CRO di Aviano, CRO2013-38) and written informed consent was obtained from all the patients. The CRO-biobanking service managed and stored all biological samples before use for the present project (authorization for analyses obtained through protocol number 6825/D). 


\section{Assessment of Radiotherapy Toxicity}

Toxicity was assessed using the Common Terminology Criteria for Adverse Events version 3.0, and divided into acute toxicity (during treatment), early toxicity (1-6months from the end of RHR) and late toxicity (>6months from the end of RHR).

Acute toxicity was assessed weekly during radiation. Following completion of radiation treatment, patients were reviewed at 1, 3, 6 (early toxicity), 8 and 12 months in the first year (late toxicity) and every 4 months from the start of second year or before for clinical need. All respiratory toxicities outcomes were analyzed: cough, dyspnea, fibrosis, pulmonitis and pulmonary thromboembolic event.

\section{Genotyping, Quality Control and Imputation/ Statistical Analysis}

\section{DNA extraction}

Germline DNA from whole blood (blood samples collected in anticoagulant-citrate-dextrose before the start of radiation treatment) was extracted from patients using the DNeasy Blood \& Tissue Kit (Qiagen, Milan, Italy) following the manufacturer's protocol. DNA quality and quantity were evaluated by agarose gel (2\%) electrophoresis and using the Invitrogen Qubit assay (Thermo Fisher Scientific, Milan, Italy). All samples extracted successfully passed quality control, based on Macrogen (https://dna.macrogeneurope.com/eng// requirements for exome sequencing.

\section{Exome sequencing}

Exome sequencing was performed in outsourcing using the service provided by Macrogen Europe (Amsterdam, The Netherlands). Briefly, the Exome Sequencing Analysis, aiming to 150x coverage, used the Illumina ${ }^{\circledR}$ SureSelect Human V7 Kit Library preparation and sequencing reaction, in an Illumina ${ }^{\circledR}$ HiSeq 2500 System, generating pair-end reads of 125 base pairs.

Illumina universal adapters were removed using Trim Galore 0.6.1 (http://www.bioinformatics.babraham.ac.uk/projects/trim_galore/). Reads with length below 15 base 
pairs and with low Phred score $(Q<20)$ were also removed using the same software. Quality control before and after these procedures were evaluated by fastQC (https://www.bioinformatics.babraham.ac.uk/projects/fastqc/).

After QC, the FASTQ file with the raw reads was aligned using Burrows-Wheeler Aligner Software Package (21), specifically the bwa-mem tool, against the Reference Human Genome version 38 (GRCh.38). We then used Picard tools (https://broadinstitute.github.io/picard/) to mark duplicates, and GATK V. 4.1.2.0 (https://software.broadinstitute.org/gatk/) for base recalibration. Strelka2 was used for variant calling, when the software was employed in the exome mode of analysis (22). Finally, we used GATK again for the exclusion of low-quality variants.

Variant annotation was performed using the ANNOVAR (23) software with databases relative to the GRCh.38 reference genome (refGene, cytoBand, wgRna, 1000g_2015_aug_all, gnomad30_genome, dbscsnv11, dbnsfp35a, clinvar_20200316 and avsnp151). R Software (24) was employed to manipulate ANNOVAR results for a descriptive and inferential analysis.

We divided the analysis into two main parts: individual, which consists in summarizing the descriptive data for each sequenced sample; and group data, which aims at drawing comparisons between patients with severe toxity versus no severe toxity. In addition, for both individual and group categories, we performed a 'Variant Enrichment Analysis'.

Principal component analysis (PCA) of variant distribution was accomplished using stats $\mathrm{R}$ packages in a non-centred approach and scaled to have unit variance before the analysis ( $R$ Core Team 2020). Variant Enrichment Analysis works similarly to Gene Enrichment Analysis for expression data: we investigated if there were statistical differences between the numbers of mutations in a pathway compared to a reference dataset. We used the R package 'ReactomePA' to obtain pathway information on each of the genes containing at least one mutation in the individual dataset (25). Then, we obtained variant data from GnomAD Exome $3.0(26)$ to use as a reference dataset. It is important to mention that, 
179 since the occurrence of some mutations may be related to specific populations, we considered for this 180 dataset only the Non-Finnish European (nfe) variant information.

181 Once we had the number of mutations per pathway in the individual dataset and in the reference 182 dataset, we used Fisher's Exact test with False discovery Rate (FDR) to identify statistical differences in 183 the number of variants. Adjusted $p$-values $<0.05$ were considered significant in this analysis. For group data, we used Venn diagrams to summarize "enriched" pathways exclusive for each group.

Human Phenotype Ontology (HPO) database was used to retrieve genes associated to the main severe toxicity response in order to extract the patients' variations from the respective genes.

\section{RESULTS}

\section{Patients}

190 Forty-nine patients were referred for radiation treatment following non-radical surgical treatment (such as partial P/D or biopsy only) between August 2014 and May 2018. Patients' charachteristics are

192 summarized in Table 1. 48 patients completed treatment as prescribed. One patient, requiring a 193 treatment break due to anemia and trombocytopenia, globally received 32 Gy in 16 fractions. One 194 patient developed infective pneumonia independent of RT, and discontinued the treatment, completing 195 the prescribed course at a later moment. 45 patients received the simultaneous boost.

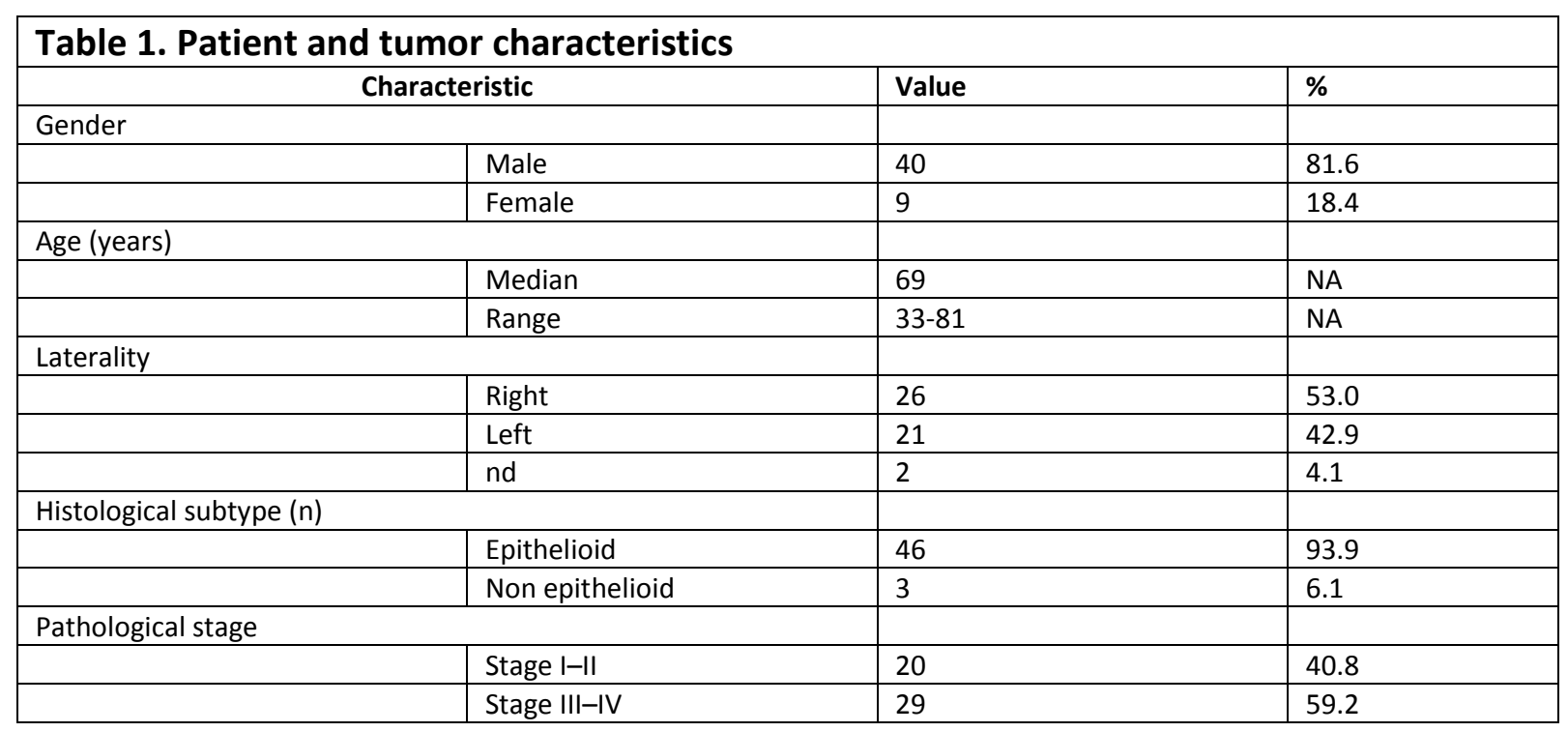




\section{Early, Acute and Late toxicity}

Reported adverse effects are summarized in Table 2, divided in events observed during treatment (early toxicity), between 1 and 6 months after the end of RT (acute toxicity), and after 6 months of follow up (late toxicity), and classified as non-pulmonary or pulmonary toxicities.

Globally, for acute and late toxicities the number of events in the non-pulmonary toxicity group tended to diminish, except for the rise in liver gamma-glutamyltransferase (GGT), commonly observed in patients treated on the right hemithorax (not shown). Fractures and pericardial effusions are typically late events, and were observed in a small number of patients, 2 and 3 cases respectively. Conversely, pulmonary toxicity events tended to develop after treatment and to last in time. One third of the patients developed low-grade cough by 6 months after RT, or at a later follow up. Dyspnea was reported in $37 \%$ of patients as acute toxicity, mainly low-grade, but became a severe toxicity in $8 \%$ of patients, as a late event. Fibrosis developed in 3 patients ( 2 severe), and pneumonitis in 7 cases, 4 of which were grade 3 . Finally, 3 thromboembolic events were reported after treatment.

Due to the impact of grade 3 pulmonary toxicities on the quality of life, for further genetic analyses patients were divided into two groups: no severeTox (NoSTox), none or tolerable toxicity (Grade 0 to 2) (grade $\leq 2)(\mathrm{N}=40)$ and severeTox $(\mathrm{STox})($ grade=3) $(\mathrm{N}=9)$ based on the development of at least one among the following: cough, dyspnea, fibrosis, pneumonitis and/or thromboembolic event. STox patients' characteristics and reported adverse effects are summarized in Table 3. No Grade 4 or 5 toxicities were recorded during treatment.

Among the 49 patients included, median OS was 25 months, and 2-year OS rate was $51.4 \%$. No significative survival differences were observed between the NoSTox and the STox group. 


\section{Table 2. Non-pulmonary and pulmonary events observed as}

Acute, Early and Late toxicities

\begin{tabular}{|c|c|c|c|}
\hline Non-pulmonary Toxicity & $\begin{array}{c}\text { Early Toxicity } \\
\text { n (\%) }\end{array}$ & $\begin{array}{c}\text { Acute Toxicity } \\
\text { n (\%) }\end{array}$ & $\begin{array}{c}\text { Late Toxicity } \\
\text { n (\%) }\end{array}$ \\
\hline $\begin{array}{cl}\text { Anemia } & \\
- & \text { Grade 1-2 } \\
\text { - } & \text { Grade } 3\end{array}$ & $\begin{array}{l}0(0) \\
1(2)\end{array}$ & $\begin{array}{l}0(0) \\
0(0)\end{array}$ & $\begin{array}{l}1(2) \\
0(0)\end{array}$ \\
\hline 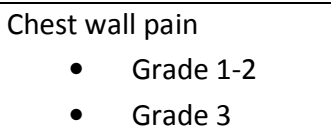 & $\begin{array}{c}12(24) \\
1(2)\end{array}$ & $\begin{array}{c}12(24) \\
0(0)\end{array}$ & $\begin{array}{c}5(10) \\
1(2)\end{array}$ \\
\hline $\begin{array}{cc}\text { Dermatitis } \\
\text { - } & \text { Grade 1-2 } \\
\text { - } & \text { Grade } \geq 3\end{array}$ & $\begin{array}{c}11(22) \\
1(2)\end{array}$ & $\begin{array}{l}2(4) \\
0(0)\end{array}$ & $\begin{array}{l}0(0) \\
0(0)\end{array}$ \\
\hline $\begin{array}{cc}\text { Fatigue } & \\
\text { - } & \text { Grade 1-2 } \\
\text { - } & \text { Grade } 3\end{array}$ & $\begin{array}{c}19(39) \\
1(2)\end{array}$ & $\begin{array}{c}10(20) \\
1(2)\end{array}$ & $\begin{array}{l}4(8) \\
1(2)\end{array}$ \\
\hline Fracture & $0(0)$ & $0(0)$ & $2(4)$ \\
\hline 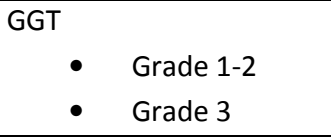 & $\begin{array}{l}9(18) \\
0(0)\end{array}$ & $\begin{array}{c}11(22) \\
1(2)\end{array}$ & $\begin{array}{c}5(10) \\
3(6)\end{array}$ \\
\hline $\begin{array}{cc}\text { Nausea/Vomiting } \\
\text { - } & \text { Grade 1-2 } \\
\text { - } & \text { Grade } 3\end{array}$ & $\begin{array}{c}23(47) \\
0(0)\end{array}$ & $\begin{array}{l}1(2) \\
0(0)\end{array}$ & $\begin{array}{l}1(2) \\
0(0)\end{array}$ \\
\hline $\begin{array}{cl}\text { Oesophagitis } \\
\text { - } & \text { Grade 1-2 } \\
\text { - } & \text { Grade 3 }\end{array}$ & $\begin{array}{c}34(69) \\
2(4)\end{array}$ & $\begin{array}{c}6(12) \\
0(0)\end{array}$ & $\begin{array}{l}1(2) \\
0(0)\end{array}$ \\
\hline $\begin{array}{cc}\text { Pericardial effusion } \\
\text { - } & \text { Grade 1-2 } \\
\text { - } & \text { Grade 3 }\end{array}$ & $0(0)$ & $\begin{array}{l}0(0) \\
1(2)\end{array}$ & $\begin{array}{l}0(0) \\
2(4)\end{array}$ \\
\hline Pulmonary Toxicity & & & \\
\hline $\begin{aligned} \text { Cough } & \\
\bullet & \text { Grade 1-2 } \\
\text { - } & \text { Grade 3 }\end{aligned}$ & $\begin{array}{l}5(10) \\
0(0)\end{array}$ & $\begin{array}{c}16(33) \\
0(0)\end{array}$ & $\begin{array}{c}14(29) \\
0(0)\end{array}$ \\
\hline $\begin{aligned} \text { Dyspnea } & \\
\text { - } & \text { Grade 1-2 } \\
\text { - } & \text { Grade 3 }\end{aligned}$ & $\begin{array}{c}9(18) \\
0(0)\end{array}$ & $\begin{array}{c}17(35) \\
1(2)\end{array}$ & $\begin{array}{l}7(14) \\
4(8)\end{array}$ \\
\hline $\begin{array}{cl}\text { Fibrosis } & \\
\text { - } & \text { Grade 1-2 } \\
\text { - } & \text { Grade 3 }\end{array}$ & N.A. & $\begin{array}{l}0(0) \\
1(2)\end{array}$ & $\begin{array}{l}1(2) \\
1(2)\end{array}$ \\
\hline $\begin{array}{c}\text { Pneumonitis } \\
\text { - } \quad \text { Grade 1-2 } \\
\text { - } \quad \text { Grade } 3\end{array}$ & $\begin{array}{l}1(2) \\
0(0)\end{array}$ & $\begin{array}{l}1(2) \\
2(4)\end{array}$ & $\begin{array}{l}1(2) \\
2(4)\end{array}$ \\
\hline Thromboembolic event & $0(0)$ & $2(4)$ & $1(2)$ \\
\hline
\end{tabular}

GTT, gamma-glutamyltransferase. 


\begin{tabular}{|c|c|c|c|c|c|c|c|c|c|}
\hline \multirow[t]{2}{*}{ Patient ID\# } & \multirow[t]{2}{*}{ Gender } & \multirow[t]{2}{*}{ Age } & \multirow[t]{2}{*}{ Laterality } & \multirow{2}{*}{$\begin{array}{l}\text { Histological } \\
\text { subtype }\end{array}$} & \multicolumn{2}{|c|}{ Pathological stage } & \multirow[t]{2}{*}{ Early Toxicity } & \multirow[t]{2}{*}{ Acute Toxicity } & \multirow[t]{2}{*}{ Late Toxicity } \\
\hline & & & & & T stage & N stage & & & \\
\hline 2 & $M$ & 71 & Right & Epithelioid & 4 & 0 & none & $\begin{array}{l}\text { Dyspnea G2, } \\
\text { Pneumonitis G3, } \\
\text { Cough G2, } \\
\text { Thromboembolic } \\
\text { eventG3 }\end{array}$ & Dyspnea G3 \\
\hline 12 & $\mathrm{M}$ & 63 & Left & Epithelioid & 2 & 0 & $\begin{array}{l}\text { Pneumonitis } \\
\text { G1 }\end{array}$ & Fibrosis G3 & none \\
\hline 17 & $M$ & 72 & Left & Epithelioid & 2 & 0 & none & none & $\begin{array}{l}\text { Thromboembolic } \\
\text { event G3 }\end{array}$ \\
\hline 20 & $\mathrm{~F}$ & 76 & Right & Epithelioid & 3 & 0 & none & none & $\begin{array}{l}\text { Pneumonitis G3, } \\
\text { Cough G2 }\end{array}$ \\
\hline 53 & $M$ & 65 & Right & Epithelioid & 2 & 0 & none & none & $\begin{array}{l}\text { Cough G2, } \\
\text { Dyspnea G2, } \\
\text { Pneumonitis G3 }\end{array}$ \\
\hline 58 & $\mathrm{~F}$ & 65 & Left & Epithelioid & 3 & 2 & none & Dyspnea G3 & $\begin{array}{l}\text { Cough G2, } \\
\text { Pneumonitis G3, } \\
\text { Dyspnea G3, }\end{array}$ \\
\hline 61 & $\mathrm{~F}$ & 72 & Right & Epithelioid & 2 & 0 & none & Dyspnea G2 & $\begin{array}{l}\text { Cough G2, } \\
\text { Dyspnea G3 }\end{array}$ \\
\hline 70 & $M$ & 78 & Left & Epithelioid & 3 & 0 & Dyspnea G2 & $\begin{array}{l}\text { Pneumonitis G3, } \\
\text { Thromboembolic } \\
\text { event G3 }\end{array}$ & none \\
\hline 94 & $M$ & 75 & Left & Epithelioid & 3 & 0 & Dyspnea G1 & Dyspnea G2 & $\begin{array}{l}\text { Pneumonitis G2, } \\
\text { Fibrosis G3 }\end{array}$ \\
\hline
\end{tabular}

\section{Genetic analysis}

The average number of variants per sample in the NoSTox group was 174,564 with 35,101 (20.12\% of the total) being specific exon variants (ExonVars). For the STox group, the average number of mutations per sample was 177,555 with 35,142 (19.79\%) ExonVars. Subsequently, ExonVars were categorized in two groups: the first group included the so-called Functional Variants (FunctVar), comprising frameshift insertion/deletion, start gain/loss and stop loss variants. The second group comprised the Impact Variants (ImpactVar), which are the mutations predicted as 'damaging' by at least one of the softwares: SIFT, Polyphen2, LRT, Mutationtaster, Mutationassessor, FATHMM, Provean, Metasvm, Metalr and M_cap.

For the NoSTox group, on average, we found 324 FunctVar and 4,022 ImpactVar, whereas, for the STox group, we identified 331 and 3,980 FunctVar and ImpactVar, respectively. We then filtered NoSTox and 
At the gene level, , in the NoSTox group, the average number of genes bearing variants was 17,994 with 12,466 (69.28\%) presenting at least one ExonVar; in the STox group mutations were detected in 18,059 genes, with 12,465 (69.02\%) genes carrying at least one ExonVar. Two-hundred sixty-seven genes had at least one Functional mutation, in the NoSTox group, and 264 in the STox group. The number of genes with at least one Impact mutation was 2,807 and 2,775 for the NoSTox and STox groups, respectively. The number of exclusive genes carrying functional or impact mutation on the STox group were 33 and 225, respectively (Supplementary Tables 1 - Datasheet 3 and 4).

Based on the results obtained considering variantions present only in the STox patients, we retrieved the pathways disrupted by the identified mutations, without, however, detecting a signifcant specific pathway involved in the clinical phenotypes observed (data not shown).

Furthermore, with the aim of applying a wider approach to pathway analysis, we performed a Variant Enrichment Analysis based on Functional and Impact mutations; 47 pathways showed a significantly increased number of Functional mutations exclusively in the NoSTox group (Table 4). For the STox group, we observed four exclusive pathways (Table 5). Regarding Impact mutations, we observed 19 and 3 exclusive pathways for NoSTox and STox group, respectively (Tables 6 and 7).

Tracing back the variants possibly involved in those pathways, we noticed 243 functional variants (along 64 genes), for the NoSTox group, and 9 variants in for the STox (in 5 genes) (supplementary tables 2 and 3). Considering the pathways with impact mutations, there are 2,908 variants (in 645 genes) present in the pathways exclusive of the NoSTox group, while only one mutation (one gene) is present in the pathways of the STox group (Supplementary tables 4 and 5).

Despite the genetic differences found between NoSTox and STox, principal component analysis (PCA) showed a homogeneous distribution of variants in both groups. Thus, no specific genetic signature was observed in NoSTox and STox (Figure 1). However, in all analyses, patient 53 showed relevant significant 
Figure 1. Principal component analysis (PCA) of genetic variants distribution in the NoSTox (red $x$ ) and STox (blue $\mathrm{x}$ ) groups. The variant distribution is homogeneous, no differences between the NoSTox and STox groups can be observed. Patient 53\# (red square) from the STox group shows ramarkable genetic distance from all other patients, regardless of whether they were NoSTox or STox, thus suggesting the presence of a specific genetic signature for this individual that is completely independent of the studied 271 phenotype. 


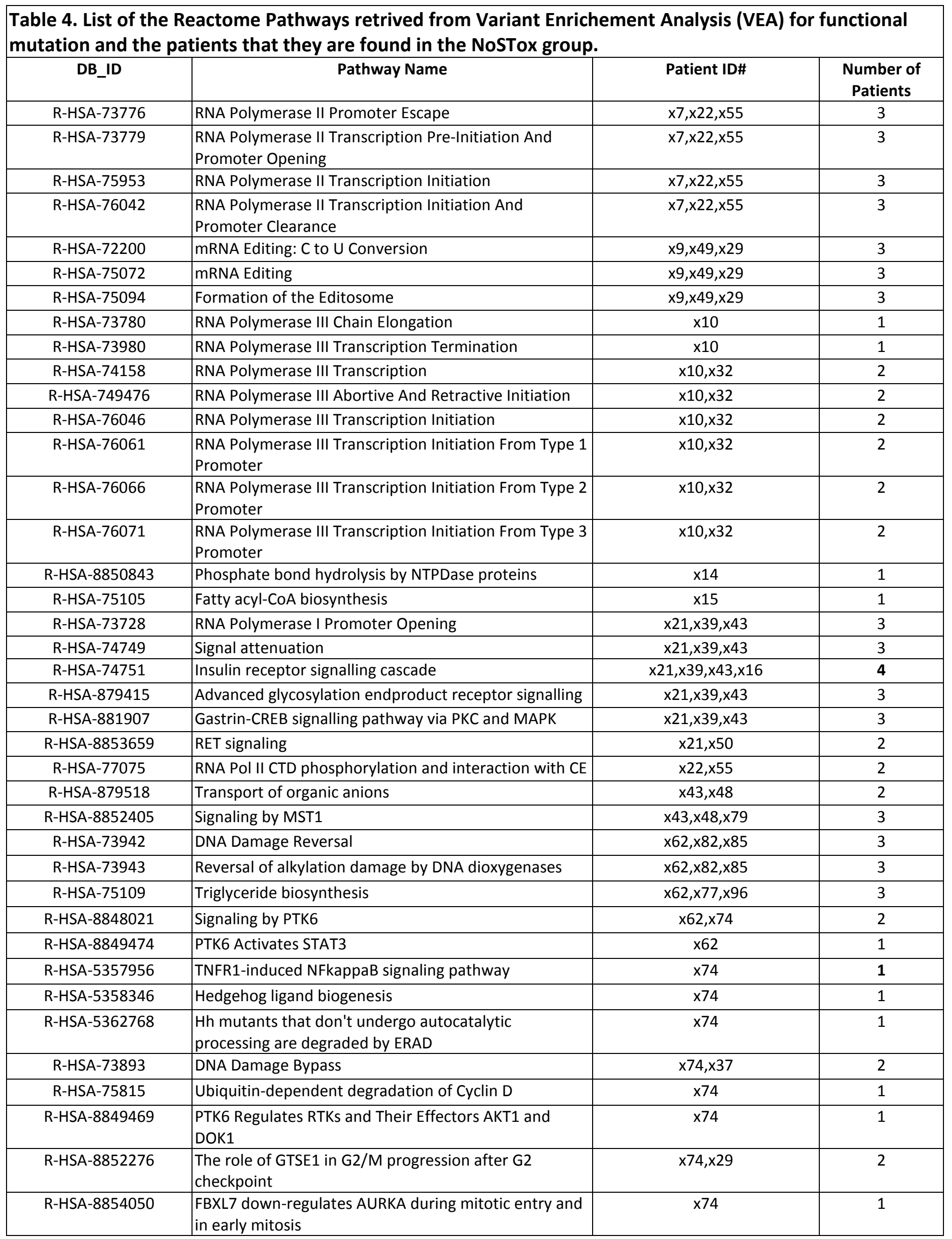




\begin{tabular}{|c|l|c|c|}
\hline R-HSA-75035 & $\begin{array}{l}\text { Chk1/Chk2(Cds1) mediated inactivation of Cyclin } \\
\text { B:Cdk1 complex }\end{array}$ & x84 \\
\hline R-HSA-73614 & Pyrimidine salvage & x87 & x87 \\
\hline R-HSA-804914 & Transport of fatty acids & x92,x37,x69 & 1 \\
\hline R-HSA-73843 & 5-Phosphoribose 1-diphosphate biosynthesis & $\mathbf{x 1 6}$ & $\mathbf{1}$ \\
\hline R-HSA-844615 & The AIM2 inflammasome & x56 \\
\hline R-HSA-8862803 & Deregulated CDK5 triggers multiple neurodegenerative \\
& pathways in Alzheimer's disease models & x88 & 1 \\
\hline R-HSA-72764 & Eukaryotic Translation Termination & x96 \\
\hline
\end{tabular}

276

Table 5. List of the Reactome Pathways retrived from Variant Enrichement Analysis (VEA) for functional mutation in the STox group.

\begin{tabular}{|c|c|c|c|}
\hline DB ID & Pathway Name & Patient ID\# & $\begin{array}{c}\text { Number of } \\
\text { Patients }\end{array}$ \\
\hline R-HSA-75205 & Clot & $\mathbf{x 2}$ & 1 \\
\hline R-HSA-72695 & $\begin{array}{l}\text { Formation of the ternary complex, and subsequently, } \\
\text { the } 43 \mathrm{~S} \text { complex }\end{array}$ & $x 53$ & 1 \\
\hline R-HSA-72702 & Ribosomal scanning and start codon recognition & $x 53$ & 1 \\
\hline
\end{tabular}

\section{Table 6. List of the Reactome Pathways retrived from Variant Enrichement Analysis (VEA) for impact mutation in the NoSTox group.}

\begin{tabular}{|c|c|c|c|}
\hline DB ID & Pathway Name & Patient ID\# & $\begin{array}{c}\text { Number of } \\
\text { Patients }\end{array}$ \\
\hline R-HSA-75035 & $\begin{array}{l}\text { Chk1/Chk2(Cds1) mediated inactivation of Cyclin } \\
\text { B:Cdk1 complex }\end{array}$ & $\begin{array}{c}x 14, x 15, x 19, x 31, x 43, x 48, x 84 \\
x 85, x 87, x 37, x 50\end{array}$ & 11 \\
\hline R-HSA-202403 & TCR signaling & $\mathrm{x} 31$ & 1 \\
\hline R-HSA-202427 & Phosphorylation of CD3 and TCR zeta chains & $\mathrm{x} 31, \mathrm{x} 16$ & 2 \\
\hline R-HSA-202430 & Translocation of ZAP-70 to Immunological synapse & $x 31, x 85, x 16$ & 3 \\
\hline R-HSA-202433 & Generation of second messenger molecules & $\mathrm{x} 31, \mathrm{x} 16$ & 2 \\
\hline R-HSA-388841 & Costimulation by the CD28 family & x31 & 1 \\
\hline R-HSA-389948 & PD-1 signaling & $\times 31, x 16$ & 2 \\
\hline R-HSA-6805567 & Keratinization & x84 & 1 \\
\hline R-HSA-844615 & The AIM2 inflammasome & $x 84$ & 1 \\
\hline R-HSA-75896 & Plasmalogen biosynthesis & $x 50, x 66, x 88$ & 3 \\
\hline R-HSA-8849468 & PTK6 Regulates Proteins Involved in RNA Processing & $\times 55, x 59, x 88$ & 3 \\
\hline R-HSA-977347 & Serine biosynthesis & $x 71$ & 1 \\
\hline R-HSA-381753 & Olfactory Signaling Pathway & x96 & 1 \\
\hline R-HSA-8853333 & Signaling by FGFR2 fusions & x96 & 1 \\
\hline
\end{tabular}




\begin{tabular}{|c|c|c|c|}
\hline DB ID & Pathway Name & Patient ID\# & $\begin{array}{c}\text { Number o } \\
\text { Patients }\end{array}$ \\
\hline R-HSA-75064 & mRNA Editing: A to I Conversion & x94 & 1 \\
\hline R-HSA-75102 & C6 deamination of adenosine & x94 & 1 \\
\hline R-HSA-77042 & Formation of editosomes by ADAR proteins & x94 & 1 \\
\hline
\end{tabular}

280 Genetics and Phenotype of the non severe toxicity group: Variant Enrichment Analysis

281 The pathways identified in the NoSTox group are mainly involved in common and non-specific biological 282 processes such as RNA processing, cell signaling, cell cycle and lipid synthesis. However, four pathways, 283 related to inflammatory and fibrotic processes, were also found to be compromised, in silico (Table 4).

284 1) The first is the R-HSA-5357956 (TNFR1-induced NFkappaB signaling pathway). One functional 285 mutation in this pathway was found in patient \#74: a frameshift insertion in the Ubiquitin C (UBC) gene (ENTREZID: 7316; exon 2: c.2051dupG or p.V685Cfs*7; without rs ID; located on chr12 at 124911720 position) in heterozygosis.

2) The second is the R-HSA-844615 (The AIM2 inflammasome) a single functional mutation related to this pathway was observed in patient \#16: a frameshift deletion in the Absent in melanoma 2 (AIM2) gene (ENTREZID: 9447; exon 5: c.712delA or p.T238Hfs*14; without rs ID; located on chr1 at 159062697 position) (Table 4). Notably, this pathway was also found among the list of impact reactome pathways in a different patient who did not develop severe pulmonary toxicities (\#84, Table 6). In this case, patient \#84 bore a mutation on exon2 (c.C278G) of PYD And CARD Domain Containing (PYCARD) (ENTREZ ID: 29108; mutation without rs ID located on chr 16 at position 31202200).

3) The third pathway identified as impaired in the NoSTox group, is the Insulin receptor signalling cascade pathway (R-HSA-74751). Three frameshift and one stopgain mutation were found in patients \#21, \#39, \#43 and \#16, respectively (Table 4). All frameshift mutations were located in the Mitogen-Activated Protein Kinase 3 (MAPK3) gene (ENTREZ ID: 5595). Patients \#39 and \#43 
carried the mutation on exon1 c.37_38insC (without rs ID, located on chr16 at position 30123172). Patient \#21 carried one mutation on exon c.38_39insC (without rs ID; located on chr16 at position 30123171). The stopgain mutation of Patient \#16 was located on exon1 of the Phosphodiesterase 3B (PDE3B) gene (ENTREZ ID: 5140; c.C447A; whitout rs ID; located chr11 at 14644522 position).

4) The last pathway predicted to be impaired in the NSTox group is related to Plasmalogen biosynthesis (R-HSA-75896), in patients \#50, \#66 and \#88 (Table 6). The gene Glyceronephosphate O-Acyltransferase (GNPAT) (ENTREZ ID: 8443) was mutated in patients \#50 and \#66, rs11122266 and rs767514222, respectively, both in exon 9. Patient \#88 carried the rs764286061 SNP in the Alkylglycerone Phosphate Synthase (AGPS) gene (ENTREZ ID: 8540).

\section{Genetics and Phenotype of the severe toxicity group: HPO and Variant Enrichment Analysis}

Using the HPO database, we selected 8 phenotypes: Pulmonary fibrosis (HP:0002206), thromboembolism (HP:0001907), pneumonia (HP:0002090), recurrent streptococcus pneumoniae infections (HP:0005366), interstitial pneumonitis (HP:0006515), bronchiolitis obliterans organizing pneumonia (HP:0011945), acute infectious pneumonia (HP:0011949) and usual interstitial pneumonia (HP:0031950). From these, 242 genes were filtered from the STox pulmonar grade 3 phenotypes: fibrosis (67), thromboembolism events (25) and pneumonia (128) (Supplementary table 6).

Patients \#12 and \#94 presented fibrosis; Patients \#2, \#17 and \#70 had thromboembolic events, and patients \#2, \#20, \#58 and \#70 were diagnosed with pneumonitis.

Twenty-five Impact Variants, along 12 genes related to fibrotic phenotypes, were found in patients \#12 and \#94, compared to the other patients. 
Two ImpactVar, along 2 genes, were associated with pneumonia in patient \#2, \#20, \#58 and \#70, compared to the other patients. Both mutations were characterized by a Combined Annotation Dependent Depletion (CADD)_Score predicting low impact on the protein.

Four Impact Variants in the myopalladin gene (MYPN) (ENTREZ ID: 84665) were associated to thromboembolic event in patient \#2, \#17 and \#70. This gene has been associated with cardiomyopathy, manly dilated cardiomyopathy (27). However, no direct associations with lung thromboembolism have been described yet, so it is probable that this gene hasbears no relation, at least not a direct one, with the observed adverse events.

Regarding to the STox Enrichment Variant Analysis, two pathways, identifyed in silico, achived potential to translate the severe toxicity phenotype.

1) A single stopgain mutation on the Serpin Family F Member 2 (SERPINF2) gene (rs374446894), involved in the Dissolution of Fibrin Clot pathway (R-HSA-75205), was altered in patient \#2, who devolveped a pulmonary thromboembolic event (Table 5).

2) A high impact non-synonymous mutation (vi1.154602065, CAAD 23, Impact Score 7/10) on the Adenosine Deaminase RNA Specific (ADAR) gene, involved in Formation of editosomes by ADAR proteins (R-HSA-77042), was carried by patient \#94, who progressed to a high grade of fibrosis (Table 7).

\section{DISCUSSION}

The employment of Radical Hemithoracic Radiotherapy in MPM has shown to confer a survival advantage but is associated with a non negligible toxicity profile in a fraction of patients $(8,11)$. This treatment should be offered to most mesothelioma affected patients as it increases 2-year survival in inoperable patients to $58 \%$, compared to the $28 \%$ rate reached by those who receive only CT or palliative radiotherapy (11). However, the toxicities associated with the treatment can have a relevant 
impact on the quality of life, at least in a fraction of patients. Thus, the early identification of patients who are at higher risk of developing severe toxicities could allow for better selection of patients eligible for radical radiotherapy with limited side effects.

Although the cause of normal tissue toxicity is multifactorial (13-15), genetic factors could play a significant role in determining radiation response (28).

The molecular events that lead to normal tissue injury are complex and span a variety of biologic processes, including oxidative stress, apoptosis, inflammation and release of proinflammatory and profibrogenic cytokines (29).

Pulmonary toxicity can heavily affect patient quality of life, causing mainly cough and dyspnea that last over time. In grade 1-2 dyspnea there is a gradual worsening like exertional breathlessness, while grade 3 toxicity has an impact also on everyday life activities. Similarly, grade 1-2 pneumonitis is often paucisymptomatic affecting only mildly the quality of life, while grade 3 pneumonitis can have a permanent impact if it evolves in severe fibrosis (30), as observed in a few of the cases in the present study. The inflammatory environment induced by RT, worsened by pneumonitis and subsequent eventual fibrosis, could induce the development of fibrin clots, potentially leading to a thromboembolic event (31), a complication which occurred in 3 of our patients, as acute and late toxic effect. This particular aspect, however, needs to be further investigated given that literature evidence is still scanty, and no predictive biomarkers for increased risk of pulmonary embolism are currently available.

The precise mechanisms underlying RP pathogenesis are unknown. They may involve radiation damage of the alveolar epithelium and capillary endothelium, or an innate immune response to tissue inflammation and injury (32-35). Radiation-induced pulmonary fibrosis, characterized by inflammatory cell infiltration, fibroblast proliferation, and excessive deposition of extracellular matrix (ECM) proteins, such as collagen, in the lung parenchyma (36-38), emerges 6 to 24 months after irradiation and continues to progress over a period of years (39). The pathological mechanisms of radiation-induced 
pulmonary fibrosis are complex and involve numerous cell types. A large number of studies have presented evidence of the involvement of several mediators in the pathogenesis of this disease $(36,40)$. A complex genetic background with a number of variations throughout the entire genome underlies variability in response to treatments. The success of individual radiotherapy depends on complex profiles, however, recent advances genotyping technology coupled with bioinformatics could offer new opportunities to identify genetic biomarkers of normal tissue radiosensitivity (41). New approaches have been developed with the advent of Next Generation Sequencing, which allows the sequencing in parallel of millions of DNA fragments obtained either from the entire genome, the so-called genome-wide association analysis (GWAS), or only from the coding fraction of the genome, the Exome, i.e Whole Exome Sequencing (WES).

Currently, neither WES analysis nor other OMICs technologies (i.e. trascriptome, proteome), have been used to assess toxicities associated to radiotherapy in lung/pleural cancer. It is important to note that population-based studies can be difficult to translate into clinical care, especially in the case of a multifactorial disease such as MPM in which surgical and radiotherapy procedures are not standardized (12) and little is known about the genetic bases leading to augmented susceptibility to this disease (4244).

In our study we performed whole exome sequencing coupled with bioinformatic analysis to study pulmonary toxicities in a group of MPM affected individuals who received the same treatment: non radical surgery and neoadjuvant chemotherapy, followed by high dose radiation therapy. Patients were divided into two groups according to the severity of the side effects developed after radical radiotherapy on the entire hemithorax: none or tolerable pulmonary toxicity (NoSTox: Grade 0 to 2 ) and more severe toxicities (STox: Grade 3). 
By employing this approach, we aimed not only at identifying genetic variants associated with the outcomes after radiotherapy, but also at unraveling the biological pathways potentially involved in the resulting observed phenotypes.

Despite the genetic differences found among NoSTox and STox, principal component analysis (PCA) showed a homogeneous distribution of variants in both groups. Thus, no global genetic specific signature was identified in NoSTox and STox.

Here we describe the different pathways we found to be associated with the radiotherapy outcomes.

\section{NoSTox group}

Variant Enrichment Analysis revealed that the pathways characterizing the NoSTox group are mostly involved with RNA processing, cell signaling, cell cycle and lipid synthesis; interestingly, also the TNFR1induced NFkappaB signaling pathway (R-HSA-5357956), appears to be involved.

Pulmonary irradiation can produce large amounts of reactive oxygen and nitrogen species that cause oxidative damage to DNA, lipids and proteins (45). The resulting tissue injury triggers an inflammatory reaction, which in turn leads to the secretion of proinflammatory factors that mantain and amplify the R-HSA-5357956): a frameshift insertion in the UBC gene (chr12: 124911720) and a nonframeshift deletion in the ovarian tumor protease 7B (OTUD7B) gene (chr1:149944731). The proteins encoded by these genes are a ubiquitinase (Ubiquitin C) and a deubiquitinase (Deubiquitinase 7B), respectively. Although overall changes in ubiquitin cellular levels in response to ionizing radiation are still little known (oppure poorly understood), Tang and colleagues showed that down-regulation of ubiquitin $\mathrm{C}$ reduces radiation-induced expression of NF-kB and inhibits its translocation into the nucleus (55), suggesting that upon irradiation, ubiquitin silencing may suppress NF-kB-induced cellular response to radiation. The deubiquitinase OTUD7B is a negative regulator of the non-canonical NF-KB pathway (56), the activiation of which is characteristically slow and persistent. Typical inducers are ligands of a subset of tumour necrosis factor receptor (TNFR) superfamily members. Largely on the basis of 
animal models studies, non-canonical NF-KB signalling has been implicated in the pathogenesis of several inflammatory diseases (57). Overexpression of another member of the ovarian tumor proteases (OTUs), OTUD4, which also negatively regulates inflammatory signalling (58), has been shown to increase radiosensitivity in non small cell lung carcinoma (59).

In addition, also the AIM2 inflammasome pathway (R-HSA-844615) has been shown to have a potential impact on NoSTox patients' phenotypes, with a frameshift deletion in the AIM2 gene (ENTREZID: 9447; exon 5: c.712delA or p.T238Hfs*14; without rs ID; located on chr1 at 159062697 position) in patient \#16; also, a mutation on exon2 (c.C278G) of PYCARD (ENTREZ ID: 29108; mutation without rs ID located on chr 16 at 31202200 position) was detected in patient \#84.

- AIM2 is an innate immune sensor that mediates assembly and activation of the inflammasome in response to double-stranded DNA breaks (60-61). In a rat model of radiation pneumonitis (RP), radiotherapy increased the mRNA expression level of AIM2, which further triggered the release of IL-1 $\beta$ and induced RP (53), suggesting that the activation of the AIM2 inflammasome by radiotherapy may contribute to the pathogenesis of RP. Interestingly, AIM2 inflammasome deficiency has been shown to protect mice from radiation-induced small intestine syndrome as well as hematopoietic failure (62).

The Insulin receptor signalling cascade (R-HSA-74751) is the pathway involved in the greatest number of patients $(n=4)$ who did not develop severe pulmonary toxicities (NSTox group).

- There is a high degree of structural homology between the insulin receptor (IR) and the insulinlike growth factor 1 (IGF-1) receptor (IGF-1R), thus these receptors signal via many common mediators (63). Ionizing radiation activates several tyrosine kinase receptors involved in DNA damage response, including IGF-1R (64), possibly promoting a pro-fibrotic state. Furthermore, dysregulation of the insulin-like growth factor (IGF) axis has been implicated in the pathogenesis of fibrosis in lung diseases (65-68). 
Insuline-like growth factor 2 (IGF-2) promotes fibrosis through IGF1R, IR, and IGF1R/IR, differentiates fibroblasts into myofibroblasts, decreases protease production and extracellular matrix degradation, and stimulates expression of two Transforming Growth Factor $\beta$ (TGF $\beta$ ) isoforms, suggesting that IGF-2 exerts pro-fibrotic effects via multiple mechanisms (69).

Recent evidence suggests that cholesterol-sphingolipid rafts might play a role in insulin signaling via IR (70). The potential contribution of lipids to insulin signaling is intriguing since the Plasmalogen biosynthesis (R-HSA-75896) pathway has also been shown to have a potential impact on NoSTox patients' phenotypes, carried by patients \#50, \#66 and \#88 who did not develop severe pulmonary toxicities.

Plasmalogens represent a class of phospholipids ubiquitously found in considerable amounts as constituents of mammalian cell membranes and significantly enriched in lipid rafts $(71,72)$, functional microdomains in cell membranes, which may affect signal transduction. Therefore, disrupting plasmalogen biosynthesis could affect trans-membrane signalling of insulin and IGFs, thus making a functional bridge between these two genes and the pathogenetic mechanisms of radiation toxicity. Furthermore, Laiakis and colleagues (73) investigated the effects of ionizing radiation on the blood level of metabolites and lipids, showing that acute exposure to $\gamma$ radiation in a mouse model induced specific mobilization of plasmalogens. Though the pathological role of plasmalogens and the biochemical pathways underlying their upregulation after radiation exposure remain to be elucidated, Braverman and Moser suggested a specific serum lipidomic biosignature as an indicator of radiation exposure (74). Coupling genetic signature to monitoring such a molecular response to radiation exposure, might have implications not only for radiation pathology but also for countermeasures and personalized medicine. Taken together these data from the NoSTox group, suggest that functional impairment in the control of the radiation induced expression of NF-kB, mainly in/of the ubiquitination/deubiquitination mechanisms, together with an impairment of the AIM2 inflammasome pathway and a dysregulation of 
the insulin-like growth factor (IGF) axis/plasmalogen biosynthesis, could modulate radiation-iduced lung inflammation preventing development of acute radiation pneumonitis and chronic radiation-induced pulmonary fibrosis.

\section{STox group}

In the attempt to unravel the adverse events in the STox group, Variant Enrichment Analysis and HPO were performed in order to establish a correlation between genetic background and clinical phenotype of the patients.

\section{Variant Enrichment Analysis}

As far as the group of individuals who developed severe pulmonary toxicities is concerned (STox), a pathway, with potential impact on these patients' phenotypes was found: the Dissolution of the Fibrin Clot pathway (RHSA-75205). Only one mutation related to this this pathway was identified: a stopgain mutation in the SERPINF2 gene (rs374446894) in patient \#2, who developed a thromboembolic event.

- Irradiation activates procoagulant activity and reduces fibrinolytic activity (75) in animal models of thoracic irradiation, suggesting the involvement of coagulation and fibrinolysis in radiationinduced pulmonary inflammation, with activation of the coagulation system promoting pulmonary fibrin deposition and contributing to the progression of pulmonary injury (76). Reduced fibrinolytic activity in the irradiated lung could be ascribed to both decreased plasminogen activator activity $(75,77)$ and increased activity of its inhibitor. The SERPINF2 gene (rs374446894) encodes a member of the serpin family of serine protease inhibitors, the alpha 2 antiplasmin ( $\alpha 2-\mathrm{AP})$, which, together with the plasminogen activator inhibitor-1 (PAI-1), is the principal direct inhibitor of fibrinolytic proteases such as plasmin, that degrades fibrin and various other proteins. Thus, $\alpha 2$-AP and PAI-1 play a major role in regulating the blood clotting pathway. PAI-1 also blocks the degradation of the extracellular matrix (78) and has been shown 
to be implicated in the progression of inflammatory and fibrotic lung diseases. Several studies have demonstrated the involvement of PAI-1 in radiation-induced tissue injury and fibrosis (79, 80). The overexpression of PAI-1 has been reported to lead to the development of radiationinduced nephrosclerosis $(81,82)$ and enteritis (83).

A recent study demonstrated that a truncated PAI-1 protein (rPAl-123) protects against radiation-induced lung injury in a murine model (84). Furthermore, PAl-1:rs7242 in the 3'untranslatedregion of PAI-1, has been shown to be a predictor of grade $\geq 3$ radiation pneumonitis before radiotherapy (85). A recent study on radiation-induced lung fibrosis in PAI-1 knockout mice has suggested an important role of PAI-1 in radiation-induced pulmonary fibrosis (86).

One large study, involving 254 women treated with breast conserving therapy, 31 of whom developed fibrosis after RT, identified 87 differentially expressed genes. Among these, the upregulation of SERPINE1, coding for PAI-1, was found (87), confirming the increased protein levels observed in fibrotic conditions (78).

PAl-1 seems to play an important role in radiation-induced tissue injury (Shioya et al, 2018), being involved in both the RP and lung fibrosis process. Likewise, Alpha 2 antiplasmin ( $\alpha 2-\mathrm{AP})$, encoded by the SERPINF2 gene, which shares most of its functions with PAI-1, could also be involved in the radiation-induced pulmonary injury observed in patient $\# 2$, who developed both a pulmonary thromboembolic event and pneumonitis.

Interestingly, a high impact non-synonymous mutation in the ADAR gene, involved in the formation of editosomes by ADAR proteins, was carried by patient \#94, who progressed to high grade fibrosis.

- The post-transcriptional modification of RNA is a key process controlling the output of the genome, and the deamination of adenosines $(A)$ to inosines $(I)$ is the prominent RNA editing event in humans, catalyzed by the Adenosine Deaminase Acting on RNA (ADAR) family of proteins (88). The effects of radiation on RNA editing are poorly understood, Liu and colleagues 
reported that upon/after $\alpha$-particles radiation, RNA editing sites change greatly and their total amount decreases after radiation (89). It has been determined that the expression of ADAR is tissue-specific, the lung being the second most highly expressing site, in terms of tissue expression $(90,91)$. The RNA editome (R-HSA-77042) analysis of idiopathic pulmonary fibrosis (IPF) and normal lungs revealed increased editing frequency in IPF compared to normal lungs, suggesting a role for disregulated editing in IPF pathogenesis (92). It has been found that the expression of ADAR1 and 2 is downregulated in fibroblasts from patients with IPF (93). The changes in expression levels of ADAR1 and ADAR2 may represent an important controlling mechanism in IPF, regulating the processing of key miRNAs such as miRNA-21. Overexpression of miRNA-21 in lung tissue and pulmonary fibroblasts from patients with IPF may be due to defective editing by ADAR (93). This miRNA targets anti-fibrosing proteins such as SMAD family member 7 (small mother against decapentaplegic), TGF beta receptor 2 (TGFßR2), TIMP Metallopeptidase Inhibitor 3 (TIMP3), Vascular endothelial growth factor A (VEGF-A) (94, 95).Crosstalk among impact pathways which control RNA editing (R-HSA-75064 and R-HSA77042) could contribute to the induction of the severe lung fibrosis observed in patient \#94.

Overall, these results suggest that, by affecting both the fibrinolytic activity and RNA editing pathways, irradiation could be responsible of the severe toxicity events reported by some patients of the STox group, who present specific mutations in genes involved in these pathways.

$\underline{\mathrm{HPO} \text { analysis }}$

Furtheromore, in an attempt to unravel the adverse events in the STox group, HPO was performed to establish a correlation between genetic background and clinical phenotype of the patients. This approach aimed at assessing, for each patient characterized by different outcomes, the genes and number of variants associated with the clinical phenotypes (i.e Dyspnea, Fibrosis, Pneumonitis and Thromboembolic events). HPO, however, did not provide conclusive evidence, since most of the variants 
observed were characterized by low CADD score and thus didn't have great impact on the genes. In addition, variants in the myopalladin gene (MYPN) were found to be associated with thromboembolic events in three patients (\#2, \#17 and \#70). However, so far this gene has been associated with dilated cardiomyopathy (27), while no associations have been reported with lung thromboembolism, so the significance of this association remains obscure.

Finally, PCA was performed with the objective of clusterizing both NoSTox and STox patients according to their genetic characteristics. Even if genetic differences were observed between the NoSTox and STox groups, PCA showed a very homogeneous distribution, with no clusters related to either the NoSTox or STox clinical groups. Therefore, a specific signature typical of the two groups could not be detected. Patient \#53 (STox) was the only one to be very distant from the NoSTox and STox clusters, without showing any specific phenotypic characteristics, so we can hypothesize that his genetic background, not related to toxicity, was simply quite distant from the other individuals analyzed, without repercussions on the studied phenotypes.

Recently, GWAS results have identified SNPs correlated with side-effect after radiotherapy in patients affected by different cancers, such as breast, prostate and lung. In our whole exome sequencing (WES) study we identified crucial pathways driving the lung response to ionizing radiations in patients affected by mesothelioma. Even if we cannot present a unifying view of the mechanisms that determine radiation toxicity of the lung, in this paper we report evidence for the key role of some specific pathways, the relevance of which is also supported by a number of published studies. They can therefore represent important starting points for more focused future investigations. Nevertheless, we are aware that our study suffers from the limitation of the small number of patients analysed, thus the results need to be validated on larger sample of patients. Moreover, RNA from patient tissues (lungs, pleura etc.) was not available, so the pathways we indentified in our study could not been further validated by RNASeq analysis. 


\section{CONCLUSION AND FUTURE PERSPECTIVES}

In conclusion, our preliminary results could pave the way for the definition of a genomic signature, i.e. a panel of predictive genomic variants, capable of supporting the management of MPM patients. By allowing for early identification of patients at high risk for treatment-dependent pulmonary toxicity, this predictive tool could play a major role in the design of new therapeutic combinations, including immunotherapy and RT. Indeed, first line nivolumab plus ipilimumab treatment has been recently proposed in unresectable MPM, to improve OS compared to chemotherapy The potential synergy of RT and immunotherapy, already observed in other cancers (96), could further improve the clinical response in MPM, but also increase the risk of side effects, shared by both treatments, such as pneumonitis (97). In this context, the pre-treatment genomic characterization we propose in this paper could help to prevent the development of severe side effects by contributing to the definition of a personalized treatment.

\section{Abbreviations}

MPM: Malignant pleural mesothelioma; P/D: Pleurectomy/Decortication; OS: Overall Survival; SNPs: single nucleotide polymorphisms; GWAS: Genome-Wide Association analysis; PET: Positron Emission Tomography; CT: Computed Tomography; RHR: Radical Hemithoracic Radiotherapy; PCA. Principal Component Analysis; HPO: Human Phenotype Ontology; NoSTox: No severeTox; STox: SevereTox; GTT: gamma-glutamyltransferase; ExonVars: Exonic Variants; FunctVar: Functional Variants; ImpactVar: Impact Variants; MYPN: Myopalladin gene; TNFa: Tumor Necrosis Factor apha; TNFR: Tumour Necrosis Factor Receptor; OTUs: Ovarian Tumor Proteases; OTUD7B: Ovarian Tumor Protease7B; AIM2: Absent in Melanoma 2; SERPINF2: Serpin Family F Member 2; ADAR: Adenosine Deaminase RNA Specific; UBC: Ubiquitin C; CADD: Combined Annotation Dependent Depletion; IR: Insulin Receptor; IGF-1: Insulin-like Growth Factor 1; IGF-2: insuline-like growth factor 2; TGF 3 : Transforming Growth Factor beta; $\alpha 2-A P$ : 
584 alpha 2 antiplasmin; PAI-1: Plasminogen Activator Inhibitor-1; IPF: Idiopathic Pulmonary Fibrosis; RP:

585 Radiation Pneumonitis.

586

587 DECLARATIONS

588 Ethics approval

589 The study has been declared to and accepted by the local Ethical Committee (Comitato Etico 590 Indipendente del CRO di Aviano, CRO-2013-38) and written informed consent was obtained from all the 591 patients. The CRO-biobanking service managed and stored all biological samples before use for the 592 present project (authorization for analyses obtained through protocol number 6825/D).

593

594 Consent for publication

595 Not applicable.

596

597 Availability of supporting data

598 The datasets supporting the conclusions of this article are included within the article and its additional 599 file see Supplementary section

600

601

Competing interests

602 The authors declare that they have no competing interests.

604 Fundings

605 This work was supported by grants from the Italian League for the Fight Against Cancer (LILT), 373 606 ASSOCIAZIONE ISONTINA LILT (Bando di Ricerca sanitaria 2017-programma 5 per mille anno 2015) and 607 from Municipality of Monfalcone (Gorizia). 
Authors' contributions

$S C$ and VB conceived the original idea and drafted the manuscript, AR acquired the data and contributed to the interpretation oft he results, RRM and LB performed genetic analysis and interpretation of the data, EM and GZ contributed to the final version of the manuscript, provided critical feedback and helped shape the research, AS, MT, EM and PZ helphed supervise the project. All authors read and approved the 614 final manuscript.

615

\section{Acknowledgments}

We are grateful to the staff of CRO-biobank for their support in patient recruitment and sample management/preparation. We thank Alessandra Knowles for critically reviewing the manuscript.

Affiliations

Biological and Environmental Sciences, University of Qatar, Doha, State of Qatar

Institute for Maternal and Child Health - IRCCS "Burlo Garofolo", Trieste, Italy

RR Moura, L Brandão

Department of Radiation Oncology, Centro di Riferimento Oncologico di Aviano (CRO) IRCCS, Aviano,

627 Italy

628 A Revelant*, E Minatel

629 Immunopathology and Biomarker Unit, Department of Translational Research, Centro di Riferimento 630 Oncologico di Aviano (CRO) IRCCS, Aviano, Italy

631 E Muraro and A Steffan 
633

634

635

636

637

638

639

640

641

642

643

644

645

646

647

648

649

650

651

652

653

654

655

M Trovò

\section{Department of Life Sciences, University of Trieste, Italy}

P Zacchi, G. Zabucchi, V Borelli

\section{References}

1. Oddone E, Bollon J, Nava CR, Bugani M, Consonni D, Marinaccio A, et al. Predictions of Mortality from Pleural Mesothelioma in Italy After the Ban of Asbestos Use. Int J Environ Res Public Health. 2020 Jan 17;17(2):607. doi: 10.3390/ijerph17020607. PMID: 31963601; PMCID: PMC7013387.

2. Ai J, Stevenson JP. Current issues in malignant pleural mesothelioma evaluation and management. Oncologist. 2014 Sep;19(9):975-84. doi: 10.1634/theoncologist.2014-0122. Epub 2014 Jul 24. PMID: 25061089; PMCID: PMC4153452.

3. Papaspyros S, Papaspyros S. Surgical management of malignant pleural mesothelioma: impact of surgery on survival and quality of life-relation to chemotherapy, radiotherapy, and alternative therapies. ISRN Surg. 2014 Feb 3;2014:817203. doi: 10.1155/2014/817203. PMID: 24624305; PMCID: PMC3929513.

4. Berzenji L, Van Schil P. Multimodality treatment of malignant pleural mesothelioma. F1000Res. 2018 Oct 22;7:F1000 Faculty Rev-1681. doi: 10.12688/f1000research.15796.1. PMID: 30410726; PMCID: PMC6198256.

5. Price A. What is the role of radiotherapy in malignant pleural mesothelioma? Oncologist. 2011;16(3):359-65. doi: 10.1634/theoncologist.2010-0185. Epub 2011 Feb 23. PMID: 21346022; PMCID: PMC3228097.

6. Minatel E, Trovo M, Polesel J, Rumeileh IA, Baresic T, Bearz A, et al. Tomotherapy after pleurectomy/decortication or biopsy for malignant pleural mesothelioma allows the delivery of 
high dose of radiation in patients with intact lung. J Thorac Oncol. 2012 Dec;7(12):1862-1866. doi: 10.1097/JTO.0b013e318272601f. PMID: 23154558.

7. Minatel E, Trovo M, Polesel J, Baresic T, Bearz A, Franchin G, et al. Radical pleurectomy/decortication followed by high dose of radiation therapy for malignant pleural mesothelioma. Final results with long-term follow-up. Lung Cancer. 2014 Jan;83(1):78-82. doi: 10.1016/j.lungcan.2013.10.013. Epub 2013 Oct 27. PMID: 24216141.

8. Minatel E, Trovo M, Bearz A, Di Maso M, Baresic T, Drigo A, et al. Radical Radiation Therapy After Lung-Sparing Surgery for Malignant Pleural Mesothelioma: Survival, Pattern of Failure, and Prognostic Factors. Int J Radiat Oncol Biol Phys. 2015 Nov 1;93(3):606-13. doi: 10.1016/j.jjrobp.2015.06.029. Epub 2015 Jun 20. PMID: 26281826.

9. Jhavar S, Pruszynski J, Gowan A, Boyle T, Deb N, Patel M. Intensity modulated radiation therapy after extra-pleural pneumonectomy for malignant pleural mesothelioma is feasible without fatal pulmonary toxicity and provides good survival. Asia Pac J Clin Oncol. 2018 Apr;14(2):e88-e94. doi: 10.1111/ajco.12680. Epub 2017 Mar 29. PMID: 28371288.

10. Thompson MR, Dumane VA, Lazarev SA, Zia Y, Rosenzweig KE. Dosimetric Correlates of Pulmonary Toxicity in Patients with Malignant Pleural Mesothelioma Receiving Radiation Therapy to the Intact Lungs. Pract Radiat Oncol. 2019 May;9(3):e331-e337. doi: 10.1016/j.prro.2018.12.008. Epub 2019 Jan 15. PMID: 30654090; PMCID: PMC6500743.

11. Trovo M, Relevant A, Polesel J, Muraro E, Barresi L, Drigo A, et al. Radical Hemithoracic Radiotherapy Versus Palliative Radiotherapy in Non-metastatic Malignant Pleural Mesothelioma: Results from a Phase 3 Randomized Clinical Trial. Int J Radiat Oncol Biol Phys. 2021 Apr 1;109(5):1368-1376. doi: 10.1016/j.ijrobp.2020.11.057. Epub 2020 Nov 28. PMID: 33259933. 
12. Rosenzweig KE. Malignant pleural mesothelioma: adjuvant therapy with radiation therapy. Ann 679 680 Transl Med. 2017 Jun;5(11):242. doi: 10.21037/atm.2017.06.25. PMID: 28706910; PMCID: PMC5497112.

13. Barnett GC, Kerns SL, Noble DJ, Dunning AM, West CM, Burnet NG. Incorporating Genetic Biomarkers into Predictive Models of Normal Tissue Toxicity. Clin Oncol (R Coll Radiol). 2015 Oct;27(10):579-87. doi: 10.1016/j.clon.2015.06.013. Epub 2015 Jul 10. PMID: 26166774.

14. Kerns SL, Dorling L, Fachal L, Bentzen S, Pharoah PD, Barnes DR, et al. Meta-analysis of Genome Wide Association Studies Identifies Genetic Markers of Late Toxicity Following Radiotherapy for Prostate Cancer. EBioMedicine. 2016 Aug;10:150-63. doi: 10.1016/j.ebiom.2016.07.022. Epub 2016 Jul 20. PMID: 27515689; PMCID: PMC5036513.

15. Kerns SL, Fachal L, Dorling L, Barnett GC, Baran A, Peterson DR, et al. Radiogenomics Consortium Genome-Wide Association Study Meta-Analysis of Late Toxicity After Prostate Cancer Radiotherapy. J Natl Cancer Inst. 2020 Feb 1;112(2):179-190. doi: 10.1093/jnci/djz075. Erratum in: J Natl Cancer Inst. 2020 Jun 1;112(6):654. PMID: 31095341; PMCID: PMC7019089.

16. Andreassen CN. Searching for genetic determinants of normal tissue radiosensitivity--are we on the right track? Radiother Oncol. 2010 Oct;97(1):1-8. doi: 10.1016/j.radonc.2010.07.018. PMID: 20817285.

17. Andreassen CN, Dikomey E, Parliament M, West CM. Will SNPs be useful predictors of normal tissue radiosensitivity in the future? Radiother Oncol. 2012 Dec;105(3):283-8. doi: 10.1016/j.radonc.2012.11.003. PMID: 23245645.

18. Andreassen CN. The future has begun in radiogenomics! Radiother Oncol. 2014 May;111(2):1657. doi: 10.1016/j.radonc.2014.04.006. Epub 2014 May 8. PMID: 24813093. 
19. Rosenstein BS. Radiogenomics: Identification of Genomic Predictors for Radiation Toxicity. Semin Radiat Oncol. 2017 Oct;27(4):300-309. doi: 10.1016/j.semradonc.2017.04.005. PMID: 28865512; PMCID: PMC5657449.

20. Kang J, Coates JT, Strawderman RL, Rosenstein BS, Kerns SL. Genomics models in radiotherapy: From mechanistic to machine learning. Med Phys. 2020 Jun;47(5):e203-e217. doi: 10.1002/mp.13751. PMID: 32418335.

21. Li H, Durbin R. Fast and accurate long-read alignment with Burrows-Wheeler transform. Bioinformatics. 2010 Mar 1;26(5):589-95. doi: 10.1093/bioinformatics/btp698. Epub 2010 Jan 15. PMID: 20080505; PMCID: PMC2828108.

22. Kim S, Scheffler K, Halpern AL, Bekritsky MA, Noh E, Källberg M, et al. Strelka2: fast and accurate calling of germline and somatic variants. Nat Methods. 2018 Aug;15(8):591-594. doi: 10.1038/s41592-018-0051-x. Epub 2018 Jul 16. PMID: 30013048.

23. Wang K, Li M, Hakonarson H. ANNOVAR: functional annotation of genetic variants from highthroughput sequencing data. Nucleic Acids Res. 2010 Sep;38(16):e164. doi: 10.1093/nar/gkq603. Epub 2010 Jul 3. PMID: 20601685; PMCID: PMC2938201R

24. Core Team. 2020. R: A Language and Environment for Statistical Computing. Vienna, Austria: R Foundation for Statistical Computing. https://www.r-project.org/.

25. Yu G, He QY. ReactomePA: an R/Bioconductor package for reactome pathway analysis and visualization. Mol Biosyst. 2016 Feb;12(2):477-9. doi: 10.1039/c5mb00663e. PMID: 26661513.

26. Karczewski KJ, Francioli LC, Tiao G, Cummings BB, Alföldi J, Wang Q, et al. The mutational constraint spectrum quantified from variation in 141,456 humans. Nature. 2020 May;581(7809):434-443. doi: 10.1038/s41586-020-2308-7. Epub 2020 May 27. Erratum in: Nature. 2021 Feb;590(7846):E53. PMID: 32461654; PMCID: PMC7334197. 
27. Meyer T, Ruppert V, Ackermann S, Richter A, Perrot A, Sperling SR, et al. Novel mutations in the sarcomeric protein myopalladin in patients with dilated cardiomyopathy. Eur J Hum Genet. 2013 Mar;21(3):294-300. doi: 10.1038/ejhg.2012.173. Epub 2012 Aug 15. PMID: 22892539; PMCID: PMC3573205.

28. Kelsey CR, Rosenstein BS, Marks LB. Predicting toxicity from radiation therapy--it's genetic, right? Cancer. 2012 Jul 15;118(14):3450-4. doi: 10.1002/cncr.26670. Epub 2011 Dec 5. PMID: 22144075; PMCID: PMC4287226.

29. Citrin DE, Mitchell JB. Mechanisms of Normal Tissue Injury From Irradiation. Semin Radiat Oncol. 2017 Oct;27(4):316-324. doi: 10.1016/j.semradonc.2017.04.001. PMID: 28865514; PMCID: PMC5653270.

30. Giuranno L, lent J, De Ruysscher D, Vooijs MA. Radiation-Induced Lung Injury (RILI). Front Oncol. 2019 Sep 6;9:877. doi: 10.3389/fonc.2019.00877. PMID: 31555602; PMCID: PMC6743286.

31. Baselet B, Sonveaux P, Baatout S, Aerts A. Pathological effects of ionizing radiation: endothelial activation and dysfunction. Cell Mol Life Sci. 2019 Feb;76(4):699-728. doi: 10.1007/s00018-0182956-z. Epub 2018 Oct 30. PMID: 30377700; PMCID: PMC6514067.

32. Marks LB, Yu X, Vujaskovic Z, Small W Jr, Folz R, Anscher MS. Radiation-induced lung injury. Semin Radiat Oncol. 2003 Jul;13(3):333-45. doi: 10.1016/S1053-4296(03)00034-1. PMID: 12903021.

33. Schaue D, McBride WH. Links between innate immunity and normal tissue radiobiology. Radiat Res. 2010 Apr;173(4):406-17. doi: 10.1667/RR1931.1. PMID: 20334512; PMCID: PMC2865470.

34. Tsoutsou PG, Koukourakis MI. Radiation pneumonitis and fibrosis: mechanisms underlying its pathogenesis and implications for future research. Int J Radiat Oncol Biol Phys. 2006 Dec 1;66(5):1281-93. doi: 10.1016/j.ijrobp.2006.08.058. PMID: 17126203. 
35. Sohn SH, Lee JM, Park S, Yoo H, Kang JW, Shin D, et al. The inflammasome accelerates radiationinduced lung inflammation and fibrosis in mice. Environ Toxicol Pharmacol. 2015 Mar;39(2):91726. doi: 10.1016/j.etap.2015.02.019. Epub 2015 Mar 7. PMID: 25805627.

36. Ding NH, Li JJ, Sun LQ. Molecular mechanisms and treatment of radiation-induced lung fibrosis. Curr Drug Targets. 2013 Oct;14(11):1347-56. doi: 10.2174/13894501113149990198. PMID: 23909719; PMCID: PMC4156316.

37. Madani I, De Ruyck K, Goeminne H, De Neve W, Thierens H, Van Meerbeeck J. Predicting risk of radiation-induced lung injury. J Thorac Oncol. 2007 Sep;2(9):864-74. doi: 10.1097/JTO.0b013e318145b2c6. PMID: 17805067.

38. Rübe CE, Uthe D, Schmid KW, Richter KD, Wessel J, Schuck A, et al. Dose-dependent induction of transforming growth factor beta (TGF-beta) in the lung tissue of fibrosis-prone mice after thoracic irradiation. Int J Radiat Oncol Biol Phys. 2000 Jul 1;47(4):1033-42. doi: 10.1016/s0360

39. Carver JR, Shapiro CL, Ng A, Jacobs L, Schwartz C, Virgo KS, et al. American Society of Clinical Oncology clinical evidence review on the ongoing care of adult cancer survivors: cardiac and pulmonary late effects. J Clin Oncol. 2007 Sep 1;25(25):3991-4008. doi: 10.1200/JCO.2007.10.9777. Epub 2007 Jun 18. PMID: 17577017.

40. Rubin P, Johnston CJ, Williams JP, McDonald S, Finkelstein JN. A perpetual cascade of cytokines postirradiation leads to pulmonary fibrosis. Int J Radiat Oncol Biol Phys. 1995 Aug 30;33(1):99109. doi: 10.1016/0360-3016(95)00095-G. PMID: 7642437.

41. Forte GI, Minafra L, Bravatà V, Cammarata FP, Lamia D, Pisciotta P, Cirrone GAP, Cuttone G, Gilardi MC, Russo G. Radiogenomics: the utility in patient selection. Transl Cancer Res. 2017;6(Suppl 5):S852-S874. doi: 10.21037/tcr.2017.06.47

42. Crovella S, Bianco AM, Vuch J, Zupin L, Moura RR, Trevisan E, et al. Iron signature in asbestosinduced malignant pleural mesothelioma: A population-based autopsy study. J Toxicol Environ 
Health A. 2016;79(3):129-41. doi: 10.1080/15287394.2015.1123452. Epub 2016 Jan 28. PMID: 26818092.

43. Borelli V, Moura RR, Trevisan E, Crovella S. NLRP1 and NLRP3 polymorphisms in mesothelioma patients and asbestos exposed individuals a population-based autopsy study from North East Italy. Infect Agent Cancer. 2015 Aug 1;10:26. doi: 10.1186/s13027-015-0022-0. PMID: 26236392; PMCID: PMC4521353.

44. Celsi F, Crovella S, Moura RR, Schneider M, Vita F, Finotto L, et al. Pleural mesothelioma and lung cancer: the role of asbestos exposure and genetic variants in selected iron metabolism and inflammation genes. J Toxicol Environ Health A. 2019;82(20):1088-1102. doi: 10.1080/15287394.2019.1694612. Epub 2019 Nov 22. PMID: 31755376.

45. Azzam El, Jay-Gerin JP, Pain D. lonizing radiation-induced metabolic oxidative stress and prolonged cell injury. Cancer Lett. 2012 Dec 31;327(1-2):48-60. doi: 10.1016/j.canlet.2011.12.012. Epub 2011 Dec 17. PMID: 22182453; PMCID: PMC3980444.

46. Huang Y, Zhang W, Yu F, Gao F. The Cellular and Molecular Mechanism of Radiation-Induced Lung Injury. Med Sci Monit. 2017 Jul 15;23:3446-3450. doi: 10.12659/msm.902353. PMID: 28710886; PMCID: PMC5523971.

47. Johnson S, Shaikh SB, Muneesa F, Rashmi B, Bhandary YP. Radiation induced apoptosis and pulmonary fibrosis: curcumin an effective intervention? Int J Radiat Biol. 2020 Jun;96(6):709-717. doi: 10.1080/09553002.2020.1739773. Epub 2020 Mar 20. PMID: 32149561.

48. Holbrook J, Lara-Reyna S, Jarosz-Griffiths H, McDermott M. Tumour necrosis factor signalling in health and disease. F1000Res. 2019 Jan 28;8:F1000 Faculty Rev-111. doi: 10.12688/f1000research.17023.1. PMID: 30755793; PMCID: PMC6352924. 
49. Shembade N, Ma A, Harhaj EW. Inhibition of NF-kappaB signaling by A20 through disruption of ubiquitin enzyme complexes. Science. 2010 Feb 26;327(5969):1135-9. doi: 10.1126/science.1182364. PMID: 20185725; PMCID: PMC3025292.

50. Hayden MS, Ghosh S. Regulation of NF-KB by TNF family cytokines. Semin Immunol. 2014 Jun;26(3):253-66. doi: 10.1016/j.smim.2014.05.004. Epub 2014 Jun 21. PMID: 24958609; PMCID: PMC4156877.

51. Moura JF, Mota JM, Leite CA, Wong DV, Bezerra NP, Brito GA, et al. A novel model of megavoltage radiation-induced oral mucositis in hamsters: Role of inflammatory cytokines and nitric oxide. Int J Radiat Biol. 2015 Jun;91(6):500-9. doi: 10.3109/09553002.2015.1021964. Epub 2015 Mar 20. PMID: 25758466.

52. Zheng J, Wang J, Pouliot M, Authier S, Zhou D, Loose DS, et al. Gene expression profiling in nonhuman primate jejunum, ileum and colon after total-body irradiation: a comparative study of segment-specific molecular and cellular responses. BMC Genomics. 2015 Nov 21;16:984. doi: 10.1186/s12864-015-2168-y. PMID: 26589571; PMCID: PMC4654820.

53. Zhang Q, Hu Q, Chu Y, Xu B, Song Q. The Influence of Radiotherapy on AIM2 Inflammasome in Radiation Pneumonitis. Inflammation. 2016 Oct;39(5):1827-34. doi: 10.1007/s10753-016-0419-y. PMID: 27525422.

54. Hill RP, Zaidi A, Mahmood J, Jelveh S. Investigations into the role of inflammation in normal tissue response to irradiation. Radiother Oncol. 2011 Oct;101(1):73-9. doi: 10.1016/j.radonc.2011.06.017. Epub 2011 Jul 2. PMID: 21726914; PMCID: PMC3197771.

55. Tang Y, Geng Y, Luo J, Shen W, Zhu W, Meng C, et al. Downregulation of ubiquitin inhibits the proliferation and radioresistance of non-small cell lung cancer cells in vitro and in vivo. Sci Rep. 2015 Mar 30;5:9476. doi: 10.1038/srep09476. PMID: 25820571; PMCID: PMC4377628. 
56. Hu H, Brittain GC, Chang JH, Puebla-Osorio N, Jin J, Zal A, et al. OTUD7B controls non-canonical NF-KB activation through deubiquitination of TRAF3. Nature. 2013 Feb 21;494(7437):371-4. doi: 10.1038/nature11831. Epub 2013 Jan 20. PMID: $23334419 ;$ PMCID: PMC3578967.

57. Sun SC. The non-canonical NF-KB pathway in immunity and inflammation. Nat Rev Immunol. 2017 Sep;17(9):545-558. doi: 10.1038/nri.2017.52. Epub 2017 Jun 5. PMID: 28580957; PMCID: PMC5753586.

58. Du J, Fu L, Sui Y, Zhang L. The function and regulation of OTU deubiquitinases. Front Med. 2020 Oct;14(5):542-563. doi: 10.1007/s11684-019-0734-4. Epub 2019 Dec 28. PMID: 31884527.

59. Wu Z, Qiu M, Guo Y, Zhao J, Liu Z, Wang H, et al. OTU deubiquitinase 4 is silenced and radiosensitizes non-small cell lung cancer cells via inhibiting DNA repair. Cancer Cell Int. 2019 Apr 15;19:99. doi: 10.1186/s12935-019-0816-z. PMID: 31011293; PMCID: PMC6466656.

60. Coornaert B, Carpentier I, Beyaert R. A20: central gatekeeper in inflammation and immunity. J Biol Chem. 2009 Mar 27;284(13):8217-21. doi: 10.1074/jbc.R800032200. Epub 2008 Nov 13. PMID: 19008218; PMCID: PMC2659177.

61. Harhaj EW, Dixit VM. Regulation of NF-KB by deubiquitinases. Immunol Rev. 2012 Mar;246(1):107-24. doi: 10.1111/j.1600-065X.2012.01100.x. PMID: 22435550; PMCID: PMC3540820.

62. Hu B, Jin C, Li HB, Tong J, Ouyang X, Cetinbas NM, et al. The DNA-sensing AIM2 inflammasome controls radiation-induced cell death and tissue injury. Science. 2016 Nov 11;354(6313):765-768. doi: 10.1126/science.aaf7532. PMID: 27846608; PMCID: PMC5640175.

63. Osher E, Macaulay VM. Therapeutic Targeting of the IGF Axis. Cells. 2019 Aug 14;8(8):895. doi: 10.3390/cells8080895. PMID: 31416218; PMCID: PMC6721736.

64. Cosaceanu D, Budiu RA, Carapancea M, Castro J, Lewensohn R, Dricu A. Ionizing radiation activates IGF-1R triggering a cytoprotective signaling by interfering with Ku-DNA binding and by 
modulating Ku86 expression via a p38 kinase-dependent mechanism. Oncogene. 2007 Apr 12;26(17):2423-34. doi: 10.1038/sj.onc.1210037. Epub 2006 Oct 9. PMID: 17043647.

65. Harrison NK, Cambrey AD, Myers AR, Southcott AM, Black CM, du Bois RM, et al. Insulin-like growth factor-I is partially responsible for fibroblast proliferation induced by bronchoalveolar lavage fluid from patients with systemic sclerosis. Clin Sci (Lond). 1994 Feb;86(2):141-8. doi: 10.1042/cs0860141. PMID: 8143424.

66. Pilewski JM, Liu L, Henry AC, Knauer AV, Feghali-Bostwick CA. Insulin-like growth factor binding proteins 3 and 5 are overexpressed in idiopathic pulmonary fibrosis and contribute to extracellular matrix deposition. Am J Pathol. 2005 Feb;166(2):399-407. doi: 10.1016/S00029440(10)62263-8. PMID: 15681824; PMCID: PMC1602317.

67. Yasuoka H, Jukic DM, Zhou Z, Choi AM, Feghali-Bostwick CA. Insulin-like growth factor binding protein 5 induces skin fibrosis: A novel murine model for dermal fibrosis. Arthritis Rheum. 2006 Sep;54(9):3001-10. doi: 10.1002/art.22084. PMID: 16947625.

68. Yasuoka H, Zhou Z, Pilewski JM, Oury TD, Choi AM, Feghali-Bostwick CA. Insulin-like growth factor-binding protein-5 induces pulmonary fibrosis and triggers mononuclear cellular infiltration. Am J Pathol. 2006 Nov;169(5):1633-42. doi: 10.2353/ajpath.2006.060501. PMID: 17071587; PMCID: PMC1780193.

69. Garrett SM, Hsu E, Thomas JM, Pilewski JM, Feghali-Bostwick C. Insulin-like growth factor (IGF)-IImediated fibrosis in pathogenic lung conditions. PLoS One. 2019 Nov 25;14(11):e0225422. doi: 10.1371/journal.pone.0225422. PMID: 31765403; PMCID: PMC6876936.

70. Ikonen E, Vainio S. Lipid microdomains and insulin resistance: is there a connection? Sci STKE. 2005 Jan 25;2005(268):pe3. doi: 10.1126/stke.2682005pe3. PMID: 15671480.

71. Honsho M, Yagita Y, Kinoshita N, Fujiki Y. Isolation and characterization of mutant animal cell line defective in alkyl-dihydroxyacetonephosphate synthase: localization and transport of 
plasmalogens to post-Golgi compartments. Biochim Biophys Acta. 2008 Oct;1783(10):1857-65.

864

865

866

867

868

869

870

871

872

873

874

875

876

877

878

879

880

881

882

883

884

885 doi: 10.1016/j.bbamcr.2008.05.018. Epub 2008 Jun 3. PMID: 18571506.

72. Pike LJ, Han X, Chung KN, Gross RW. Lipid rafts are enriched in arachidonic acid and plasmenylethanolamine and their composition is independent of caveolin-1 expression: a quantitative electrospray ionization/mass spectrometric analysis. Biochemistry. 2002 Feb 12;41(6):2075-88. doi: 10.1021/bi0156557. PMID: 11827555.

73. Laiakis EC, Strassburg K, Bogumil R, Lai S, Vreeken RJ, Hankemeier T, et al. Metabolic phenotyping reveals a lipid mediator response to ionizing radiation. J Proteome Res. 2014 Sep 5;13(9):4143-54. doi: 10.1021/pr5005295. Epub 2014 Aug 15. PMID: 25126707; PMCID: PMC4156265.

74. Braverman NE, Moser AB. Functions of plasmalogen lipids in health and disease. Biochim Biophys Acta. 2012 Sep;1822(9):1442-52. doi: 10.1016/j.bbadis.2012.05.008. Epub 2012 May 22. PMID: 22627108.

75. Ts'ao CH, Ward WF, Port CD. Radiation injury in rat lung. III. Plasminogen activator and fibrinolytic inhibitor activities. Radiat Res. 1983 Nov;96(2):301-8. PMID: 6685887.

76. Sawada M. Coagulation and fibrinolysis systems in bronchoalveolar lavage fluid in irradiated lung of rabbits. Nihon Kyobu Shikkan Gakkai Zasshi. 1993 Dec;31(12):1515-21. Japanese. PMID: 8121087.

77. Raymond J, Yoon SC, Ts'ao CH. Stimulation of radiation-impaired plasminogen activator release by phorbol ester in aortic endothelial cells. Proc Soc Exp Biol Med. 1990 Nov;195(2):213-7. doi: 10.3181/00379727-195-43137. PMID: 2236104.

78. Ghosh AK, Vaughan DE. PAI-1 in tissue fibrosis. J Cell Physiol. 2012 Feb;227(2):493-507. doi: 10.1002/jcp.22783. PMID: 21465481; PMCID: PMC3204398. 
79. Hageman J, Eggen BJ, Rozema T, Damman K, Kampinga HH, Coppes RP. Radiation and transforming growth factor-beta cooperate in transcriptional activation of the profibrotic plasminogen activator inhibitor-1 gene. Clin Cancer Res. 2005 Aug 15;11(16):5956-64. doi: 10.1158/1078-0432.CCR-05-0427. PMID: 16115939.

80. Zhao W, Spitz DR, Oberley LW, Robbins ME. Redox modulation of the pro-fibrogenic mediator plasminogen activator inhibitor-1 following ionizing radiation. Cancer Res. 2001 Jul 15;61(14):5537-43. PMID: 11454704.

81. Brown NJ, Nakamura S, Ma L, Nakamura I, Donnert E, Freeman M, Vaughan DE, Fogo AB. Aldosterone modulates plasminogen activator inhibitor-1 and glomerulosclerosis in vivo. Kidney Int. 2000 Sep;58(3):1219-27. doi: 10.1046/j.1523-1755.2000.00277.x. PMID: 10972684.

82. Oikawa T, Freeman M, Lo W, Vaughan DE, Fogo A. Modulation of plasminogen activator inhibitor-1 in vivo: a new mechanism for the anti-fibrotic effect of renin-angiotensin inhibition. Kidney Int. 1997 Jan;51(1):164-72. doi: 10.1038/ki.1997.20. PMID: 8995730.

83. Vozenin-Brotons MC, Milliat F, Linard C, Strup C, François A, Sabourin JC, et al. Gene expression profile in human late radiation enteritis obtained by high-density cDNA array hybridization. Radiat Res. 2004 Mar;161(3):299-311. doi: 10.1667/rr3128. PMID: 14982484.

84. Chung EJ, McKay-Corkum G, Chung S, White A, Scroggins BT, Mitchell JB, Mulligan-Kehoe MJ, Citrin D. Truncated Plasminogen Activator Inhibitor-1 Protein Protects From Pulmonary Fibrosis Mediated by Irradiation in a Murine Model. Int J Radiat Oncol Biol Phys. 2016 Apr 1;94(5):116372. doi: 10.1016/j.ijrobp.2015.11.044. Epub 2015 Dec 14. PMID: 26883561; PMCID: PMC4838903.

85. Liu B, Tang Y, Yi M, Liu Q, Xiong H, Hu G, Yuan X. Genetic variants in the plasminogen activator inhibitor-1 gene are associated with an increased risk of radiation pneumonitis in lung cancer 
patients. Cancer Med. 2017 Mar;6(3):681-688. doi: 10.1002/cam4.1011. Epub 2017 Feb 17. PMID: 28211612; PMCID: PMC5345627.

86. Shioya S, Masuda T, Senoo T, Horimasu Y, Miyamoto S, Nakashima T, et al. Plasminogen activator inhibitor-1 serves an important role in radiation-induced pulmonary fibrosis. Exp Ther Med. 2018 Oct;16(4):3070-3076. doi: 10.3892/etm.2018.6550. Epub 2018 Aug 1. PMID: 30214528; PMCID: PMC6125865.

87. Landmark-Høyvik H, Dumeaux V, Reinertsen KV, Edvardsen H, Fosså SD, Børresen-Dale AL. Blood gene expression profiling of breast cancer survivors experiencing fibrosis. Int J Radiat Oncol Biol Phys. 2011 Mar 1;79(3):875-83. doi: 10.1016/j.ijrobp.2010.09.052. Epub 2010 Dec 2. PMID: 21129856.

88. Walkley CR, Li JB. Rewriting the transcriptome: adenosine-to-inosine RNA editing by ADARs. Genome Biol. 2017 Oct 30;18(1):205. doi: 10.1186/s13059-017-1347-3. PMID: 29084589; PMCID: PMC5663115.

89. Liu Q, Li H, You L, Li T, Li L, Zhou P, et al. Genome-wide identification and analysis of A-to-I RNA editing events in the malignantly transformed cell lines from bronchial epithelial cell line induced by $\alpha$-particles radiation. PLoS One. 2019 Jun 3;14(6):e0213047. doi: 10.1371/journal.pone.0213047. PMID: 31158229; PMCID: PMC6546236.

90. Paul MS, Bass BL. Inosine exists in mRNA at tissue-specific levels and is most abundant in brain mRNA. EMBO J. 1998 Feb 16;17(4):1120-7. doi: 10.1093/emboj/17.4.1120. PMID: 9463389; PMCID: PMC1170460.

91. Orlandi C, Barbon A, Barlati S. Activity regulation of adenosine deaminases acting on RNA (ADARs). Mol Neurobiol. 2012 Feb;45(1):61-75. doi: 10.1007/s12035-011-8220-2. Epub 2011 Nov 20. PMID: 22113393. 
92. Soundararajan R, Stesrns TM, Griswold AL, Metha A, Czachor, Fukumoto J, Loket RF, et al. De Novo Analysis Of Human Idiopathic Pulmonary Fibrosis Lungs Reveals Dysregulated Canonical ATo-G Editing Events At 3'Utrs And Microrna Target Sites. Am J Resp Crit Care Med. 2016; 193: 2016 A4544-A4544. B110. NOVEL THERAPIES AND TARGETS IN FIBROSIS.

93. Díaz-Piña G, Ordoñez-Razo RM, Montes E, Páramo I, Becerril C, Salgado A, et al. The Role of ADAR1 and ADAR2 in the Regulation of miRNA-21 in Idiopathic Pulmonary Fibrosis. Lung. 2018 Aug;196(4):393-400. doi: 10.1007/s00408-018-0115-9. Epub 2018 Apr 10. PMID: 29637273.

94. Pandit KV, Corcoran D, Yousef H, Yarlagadda M, Tzouvelekis A, Gibson KF, et al. Inhibition and role of let-7d in idiopathic pulmonary fibrosis. Am J Respir Crit Care Med. 2010 Jul 15;182(2):2209. doi: 10.1164/rccm.200911-16980C. Epub 2010 Apr 15. PMID: 20395557; PMCID: PMC2913236.

95. Pandit KV, Milosevic J, Kaminski N. MicroRNAs in idiopathic pulmonary fibrosis. Transl Res. 2011 Apr;157(4):191-9. doi: 10.1016/j.trsl.2011.01.012. Epub 2011 Feb 4. PMID: 21420029.

96. Maity A, Mick R, Rengan R, Mitchell TC, Amaravadi RK, Schuchter LM, et al. A stratified phase I dose escalation trial of hypofractionated radiotherapy followed by ipilimumab in metastatic melanoma: long-term follow-up and final outcomes. Oncoimmunology. 2021 Jan 31;10(1):1863631. doi: 10.1080/2162402X.2020.1863631. PMID: 33643689; PMCID: PMC7872096.

97. Sha CM, Lehrer EJ, Hwang C, Trifiletti DM, Mackley HB, Drabick JJ, et al. Toxicity in combination immune checkpoint inhibitor and radiation therapy: A systematic review and meta-analysis. Radiother Oncol. 2020 Oct;151:141-148. doi: 10.1016/j.radonc.2020.07.035. Epub 2020 Jul 24. PMID: 32717359. 


\section{Supplementary}

Additional datasets supporting the conclusions of this article (Supplementary Table 1.-5) are included within these additional files: Supp_table_1.xls and Suppl_tables_2_3_4_5.xlsx

\section{Supplementary Table 1.}

Legend: Excel file (Supp_table_1.xIs) with 4 datasheet.

Datasheet 1-Exclusive FunctVar STox: List of 43 FunctVar exclusive for STox group.

Datasheet 2-Exclusive ImpactVar STox: List of 338 ImpactVar exclusive for STox group.

Datasheet 3 - Genes with FunctVar STox: List of 476 FunctVar from 33 genes exclusive from STox group.

Datasheet 4 - Genes with ImpactVar STox: List of 937 ImpactVar from 225 genes exclusive from STox group.

Variant ID (vi) without rs were described by vi crhomosome and position (vi17.69277741; i.e. variant in chromosome 17 located on 69277741). Damage prediction were calculated by the mutation score of : SIFT, Polyphen2, LRT, Mutationtaster, Mutationassessor, FATHMM, Provean, Metasvm, Metalr and M_cap databases. Allele frequency (AF) were accessible by GnomAD Exome 3.0.

Supplementary Tables 2, 3, 4 and 5.

Legend: Excel file (Suppl_tables_2_3_4_5.xlsx) with 4 datasheet

Datasheet 1-Supplementary Table 2. List of the variants present in the functional pathways found in the non-toxicological effect group.

Datasheet 2-Supplementary Table 3. List of the variants present in the functional pathways found in the toxicological effect group.

Datasheet 3- Supplementary Table 4. List of the variants present in the impact pathways found in the non-toxicological effect group. 
Supplementary Table 6. HPO analysis of STox pulmonar grade 3 phenotypes: Dyspnea (D), Fibrosis (F), Pneumonitis (P) and Thromboembolic Event (TE).

\begin{tabular}{|c|c|c|c|c|c|c|c|c|c|}
\hline \multirow[b]{2}{*}{ Patient ID\# } & \multicolumn{4}{|c|}{$<6$ months } & \multicolumn{4}{|c|}{$>6$ month } & \multirow{2}{*}{$\begin{array}{l}N^{\circ} \text { ImpactVar related to HPO database } \\
\text { phenotypes }\end{array}$} \\
\hline & $\mathrm{D}$ & $\mathrm{F}$ & $P$ & $\mathrm{TE}$ & $\mathrm{D}$ & $\mathrm{F}$ & $\mathrm{P}$ & $\mathrm{TE}$ & \\
\hline 2 & & & $\mathrm{X}$ & $\mathrm{x}$ & $\mathrm{x}$ & & & & $\begin{array}{l}4 \text { Impactvar at the myopalladin gene (MYPN*) were associated } \\
\text { to Thromboembolic event } \\
2 \text { ImpactVar, along } 2 \text { genes**, were associated to the } \\
\text { pneumonia }\end{array}$ \\
\hline 12 & & $\mathrm{X}$ & & & & & & & 25 ImpactVar, along 12 genes related to fibrotic phenotypes \\
\hline 17 & & & & & & & & $\mathrm{X}$ & $\begin{array}{l}4 \text { Impactvar at the myopalladin gene (MYPN*) were associated } \\
\text { to Thromboembolic event }\end{array}$ \\
\hline 20 & & & & & & & $\mathrm{x}$ & & $\begin{array}{l}2 \text { ImpactVar, along } 2 \text { genes**, were associated to the } \\
\text { pneumonia }\end{array}$ \\
\hline 53 & & & & & $\mathrm{X}$ & & $\mathrm{X}$ & & No association \\
\hline 58 & $x$ & & & & & & $\mathrm{x}$ & & $\begin{array}{l}2 \text { ImpactVar, along } 2 \text { genes**, were associated to the } \\
\text { pneumonia }\end{array}$ \\
\hline 61 & & & & & $\mathrm{X}$ & & & & No association \\
\hline 70 & & & $\mathrm{x}$ & $\mathrm{x}$ & & & & & $\begin{array}{l}4 \text { Impactvar at the myopalladin gene (MYPN*) were associated } \\
\text { to Thromboembolic event } \\
2 \text { ImpactVar, along } 2 \text { genes**, were associated to the } \\
\text { pneumonia }\end{array}$ \\
\hline 94 & & & & & & $\mathrm{x}$ & & & 25 ImpactVar, along 12 genes related to fibrotic phenotypes \\
\hline
\end{tabular}

*No association with lung thromboembolism

$984 * *$ CADD_Score predicting low impact on the protein. 


\section{Supplementary Files}

This is a list of supplementary files associated with this preprint. Click to download.

- Supptable1.xls

- Suppltables2345.xlsx 